\title{
OXFORD
}

\section{Physical Therapy}

Is the Brief-BESTest brief enough? Suggested modifications based on structural validity and internal consistency.

\begin{tabular}{|r|l|}
\hline Journal: & Physical Therapy \\
\hline Manuscript ID & PTJ-2018-0336.R2 \\
\hline Manuscript Category: & Original Research - Observational/Prognostic \\
\hline Section: & Balance and Falls \\
\hline Keywords: & $\begin{array}{l}\text { Balance, Gait Disorders: Neurologic, Neurologic Manifestations, } \\
\text { Rehabilitation Centers, Measurement: Applied }\end{array}$ \\
\hline & \\
\hline
\end{tabular}

\section{SCHOLARONE"}

Manuscripts 
1 Is the Brief-BESTest brief enough? Suggested modifications based on structural validity and 2 internal consistency

3

4

5

6

7

8 


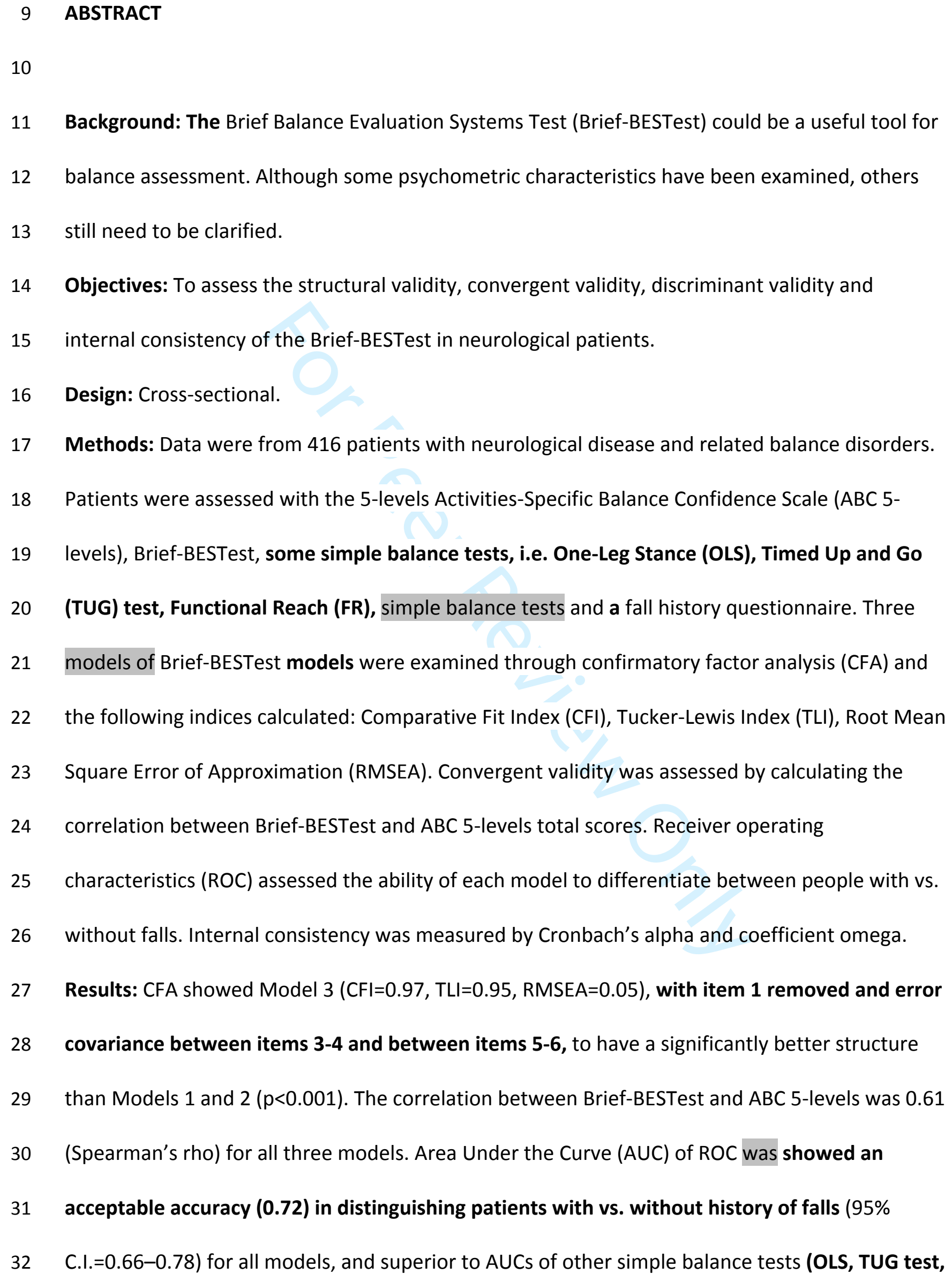


FR). Cronbach's alpha was good for Brief-BESTest Models 1 (0.92) and 3 (0.92), but omega was $>0.80$ only for Model 3 .

Limitations: Heterogeneous sample size was a heterogeneous population.

Conclusions: The Brief-BESTest, after some changes, shows good validity and internal

consistency in patients affected by different balance disorders, after applying some changes.

\section{Contribution of the Paper:}

- $\quad$ Although some psychometric characteristics of the Brief-BESTest have been examined in previous studies, other properties such as validity still need to be clarified.

- $\quad$ This study shows that the Brief-BESTest has good validity and internal consistency in patients affected by different balance disorders, after applying some changes: removal of item 1 and using an appropriate weighting method for the calculation of the total score.

- $\quad$ This study confirms the ability of the Brief-BESTest to distinguish between people with vs. without history of falls, in contrast to other simple balance tests. Moreover, it highlights once again the superiority of a clinical scale composed of several items compared to single-item measures such as the TUG test and OLS.

Keywords: Brief-Balance Evaluation Systems Test, balance assessment, confirmatory factor analysis, structural validity, internal consistency. 


\section{5 \\ INTRODUCTION}

56

Balance disorders are a common finding in a broad spectrum of neurological disorders and are characterized by a heterogeneous set of signs and symptoms. Patients with balance disorders experience a reduction in mobility, activities of daily living and muscle strength, leading to increased risk of falls $[1,2,3,4]$. Thus, balance assessment is crucial and requires standardized measurement tools that can monitor equilibrium regardless of the pathology. Unfortunately, no gold standard exists for evaluating balance [5], and no consensus on which assessment tools to use in clinical practice $[6,7]$.

A variety of clinical measures has been developed to evaluate different aspects of balance. While simple balance tests such as the Timed Up and Go test, One Leg Stance, and Functional Reach provide accurate evaluation of a single task, they are not able to do not give information on multifactorial mechanisms related to postural stability [8]. On the contrary, balance scales which include multiple tasks can provide a more complete picture of balance control in all its complexity $[9,10,11]$.

One of the most recent balance scales is the BESTest, a 36-item scale developed to identify impairments in six balance control subsections, which it has been shown to be a valid and reliable tool [8]. However, one of its drawbacks is that it is time-consuming to administer [12]. For this reason, shorter versions have been proposed such as the Mini-BESTest [12] and the Brief-BESTest [13]. In particular, the Brief-BESTest, an 8-item version of the original scale, has demonstrated good to excellent psychometric properties $[8,13,14,15]$. It is less time-consuming [16] and more feasible than its parent scale in clinical settings [15], while it encompasses and should adequately evaluate all subsections of balance endorsed by the BESTest $[13,17,18]$. 
78 However, the latter hypothesis was rejected through exploratory factor analysis dismantled the

latter hypothesis, demonstrating that the Brief-BESTest actually has at most two subsections, or dimensions [19]. Furthermore, Bravini et al. [14] showed by Rasch analysis that all items of the Brief-BESTest except for item 1 account for the same underlying theoretical construct and indicated that the Brief-BESTest should in fact be considered as unidimensional. Therefore, the authors suggested the adoption of a 7-item version of the test.

Although some psychometric characteristics of the Brief-BESTest, such as the internal consistency $[13,14]$, reliability $[14,17,20]$ and sensitivity to change $[14,20]$, have been investigated in previous studies, other properties still need to be clarified. In particular, the BriefBESTest structure has not yet been investigated with undergone confirmatory factor analysis (CFA). This statistical tool provides information on possible independent factors and can be very useful for developing shortened forms of an evaluating instrument [21,22]. Finally, the BriefBESTest seems to have good sensitivity and accuracy in identifying retrospectively people who have had at least one fall $[13,17]$. However, these findings are based only on small samples of patients with multiple sclerosis [13] or Parkinson's disease [17].

The We aimed in of the present study was to fill the existing knowledge gap by examining the structural validity, convergent validity and discriminant validity of the Brief-BESTest in a large group of patients with a variety of balance disorders. In particular, we hypothesized that:

1) among the three models of the Brief-BESTest presented in the literature $[13,14,19]$, the 7 -item version would be the one with the best structural validity;

2 ) in spite of its conciseness, the 7-item model [14] would have the same ability as the other two Brief-BESTest models to predict patients at risk of falls; discriminate between people with vs. without a history of falls; 
1013 3) in discriminating between people with vs. without a history of falls, the Brief-BESTest would be 102 superior to other simple balance tests such as One Leg Stance, Timed Up and Go test and 103 Functional Reach.

Participants

\section{METHODS}

This was an observational retrospective study conducted in a group of 416 patients affected by different neurological diseases: 186 females and 230 males; mean age $66.5 \pm 16.0$ years (mean \pm

standard deviation) consecutively admitted for in-patient rehabilitation at the XXXXXXX between

February 2014 and April 2017. Patients' clinical and treatment data were extracted from the electronic medical record system and transferred to a specific database (Microsoft Excel).

Patients were stratified into different groups according to their diagnosis: 118 with Parkinson's disease, 79 with acute stroke, 43 with sensorimotor polyneuropathy, 32 with cerebellar ataxia, 32 with diffuse encephalopathy, 31 with chronic stroke, 21 with multiple sclerosis, 19 with traumatic brain injury, 16 with vestibular disorder, 13 with neuromuscular disorders, 12 with central nervous system neoplasm. Inclusion criteria were: a) ability to maintain an upright position without support for at least 5 seconds; b) ability to understand the required motor tasks; c) no hip or knee replacement surgery within the previous 6 months. Exclusion criteria were: a) musculoskeletal injury limiting the ability to walk; b) any other serious cardio-respiratory problem. The study was carried out in conformity with the Declaration of Helsinki of the World Medical Association and the guidelines for retrospective studies [23]. The local scientific and ethics committee approved the study. 
125 Assessment tools

126 Patients' demographic and clinical characteristics were gathered by Aa team of trained physical 127 therapists engaged in clinical practice collected patients' demographic and clinical

- Fall history

A history of falls over the past 6 months was obtained from patients at admission through patient interview. A fall was defined as an unintentional event in which any part of the body came into contact with the ground [10]. Patients who reported two or more falls in the defined period were classified as 'fallers' [24]. A fall history was not recorded taken in the case of for patients with acute stroke at the time of admission.

\section{- Brief-BESTest}

The Brief-BESTest is an 8-item scale with each item scored on a 4-level rating scale from 0 (severe balance impairment) to 3 (no balance impairment). Its items cover the six subsections of the original BESTest (biomechanical constraints, stability limits/verticality, anticipatory postural responses, postural responses, sensory orientation, stability in gait); the maximum total score is 24 [13]. The Brief-BESTest requires less time and equipment to administer than the BESTest and the Mini-BESTest; thus, the Brief-BESTest seems to be more feasible for clinical use [17]. 143 - Simple balance tests 
144 During administration of the Brief-BESTest, we recorded the time required by patients to 145 complete item 3 (left One Leg Stance), 4 (right One Leg Stance) and 8 (Timed Up and Go test) and 146 the distance covered by patients during item 2 (Functional Reach). This allowed us to obtain the ${ }_{1} 147$ scores of three additional simple balance tests: One Leg Stance (OLS) [25,26], Timed Up and Go

(TUG) test $[27,28]$ and Functional Reach (FR) $[29,30]$.

\section{- Activities-specific Balance Confidence Scale}

The short version of the Activities-specific Balance Confidence Scale (ABC) is a self-reported 16-

item questionnaire that scores the perceived level of balance confidence when performing common activities of daily living [31]. We used the 5-levels rating version of rating (ABC 5-levels) [32] in which each item is scored from 0 (no confidence) to 4 (fully confident), giving a total score range 0-64.

\section{Data analysis}

Descriptive statistics were used to describe mean demographic and balance performance characteristics of the entire sample and of the two smaller subgroups, classified as fallers and non-fallers. The analysis of discriminant validity was conducted only in these two subgroups, i.e. those patients who had a history of falls available. These values were also determined separately both for fallers and non-fallers. For each item of the Brief-BESTest we calculated: median value, spread $\left(25^{\text {th }}-75^{\text {th }}\right.$ percentiles), skewness and kurtosis. Floor and ceiling effects were analyzed by calculating the percentage of individuals obtaining the lowest and the highest score for each scale item. In order to detect differences in clinical characteristics between fallers and non-fallers, the Chi-square $\left(\chi^{2}\right)$ test was used for two parameters, sex and use of walking aids, while the Mann-Whitney U-test was used for age, OLS, TUG test, FR, total score of Brief- 
167 BESTest and total score of $A B C 5$-levels. Significance was set at $p<0.05$. All analyses were 168 performed using STATA 13.0 software (StataCorp LLC, College Station, Texas, USA).

\section{Structural validity}

Structural validity is usually assessed through CFA [33]. CFA assesses the degree to which

responses on a $\mathrm{p} \times 1$ vector of observable random variables (the Brief-BESTest items) can be used to assign a value to one or more unobserved variable(s) (balance subsections). For this purpose, a specific mathematical model is identified and fitted to the patients' data.

The original model (Model 1) of the Brief-BESTest [13] comprises one factor with 8 independent items that contribute with the same weights to the total score. In the recent literature, two additional models of Brief-BESTest have been presented. Model 2 was designed based on [19]. It includes two factors: one named "static balance" that comprises items 1 and 2, and another called "dynamic balance" that contains items 3 to 8 . As demonstrated by the authors, items 5 and 6 showed local dependence, so Model 2 was designed allowing correlation between the errors of these items. In Model 3, was drawn up without item 1 was dropped, as suggested by [14]. In this 7-item model, the error of item 3 was allowed to correlate with that of item 4 and the error of item 5 with that of item 6.

For all models, the score of each item ranges from 0 to 3 . Then the total score was is obtained by multiplying the rated score by the coefficient fitted for each model (see below formula and supplementary data). In order to allow comparison of the score models, we adjusted the coefficients so have been adjusted as to maintain a total score in the range 0 to 24 . Appendix 1 summarizes the item structure of the three models and their total score. 
Preliminary analysis conducted on Model 3 showed similar CFA results for patients who used a walking aid and those who did not. For this reason, we decided to consider the entire sample independently of the walking condition in creating our models.

We examined t $\mathbf{t}$ The structural validity of these three models (from here on Model 1, 2 and 3) was examined through CFA using Structural Equation Modeling (SEM). In view of the very low occurrence of missing data (maximum $0.4 \%$ ), cases with missing data were removed from the analysis. $\chi^{2}$ was used to identify whether the model fitted the data well. In addition, we assessed the models' goodness of fit using the following indices: Comparative Fit Index (CFI) [34], TuckerLewis Index (TLI), Root Mean Square Error of Approximation (RMSEA) [35] and the Standardized Root Mean Square Residual (SRMR) [34]. The criteria adopted to assess goodness of fit performance were: a) CFI and TLI values $\geq 0.95$; b) RMSEA value $<0.06$; and c) SRMR value $\leq 0.08$ [36].

The goodness of fit parameters of the three models were compared by computing the $\chi^{2}$ difference tests of each model pair, calculated as a $\chi^{2}=\chi^{2}{ }_{2}-\chi^{2}{ }_{1}$ with $\mathrm{df}=\mathrm{df}_{2}-\mathrm{df}_{1}$.

The standardized factor loadings of the models (i.e. the coefficients of the fitted model) were then transformed into weights that can be applied when scale scores for an individual are calculated. They were calculated with a non-refined method called "Weighted Sum Scores" [37]; these weights do not change the scale range [38].

\section{Internal consistency}

The internal consistency of the three Brief-BESTest models was measured by Cronbach's alpha and the coefficient omega for congeneric models [39]. Cronbach's alpha measures the extent to which the items consistently measure the same construct, with the value $\geq 0.80$ indicating good 
211 internal consistency [40]. The coefficient omega is the ratio of the true score variance and the 212 total variance of the scale. Interpretation of coefficient omega is similar to that of Cronbach's 213 alpha [41].

\section{Convergent validity}

We used the correlation between the three models of Brief-BESTest and the ABC 5-levels total 20

score to assess the convergent validity. The $A B C$ scale led to rate rates the balance self-efficacy of patients [31]. This is associated with measures of balance [32], walking capacity [42], functional mobility [43], Activities of Daily Living performance [44], and perceived health status [45]. The choice to use the $A B C$ as a competitor an external criterion was also based on the need to avoid the comparisons ofng the three models with a scale that had items similar to the BriefBESTest. The correlation was assessed by means of Spearman's rho: coefficients $<0.30$ were interpreted as weak, those between 0.30 and 0.49 as moderate, and those $\geq 0.50$ as strong correlations [46].

\section{Discriminant validity}

To assess the ability of the three Brief-BESTest models to distinguish between 'fallers' and 'nonfallers', receiver operating characteristic $(R O C)$ curves were computed, by plotting sensitivity on the $x$-axis against 1 - specificity on the $y$-axis. In our study, sensitivity was calculated as the number of patients correctly identified as 'fallers' and specificity as the number of patients correctly identified as 'non-fallers'. The optimal cut-off value was chosen on the ROC curve at the point that jointly maximized sensitivity and specificity [47]. For each ROC, the area under the 
233 curve (AUC) and the positive and negative likelihood ratios ( $L R+$ and $L R-$ ) were computed to

maximize the cut off scores. Low, moderate and high accuracy of discrimination were defined

235 respectively as $A \cup C<0.70,0.70<A \cup C<0.90$, and $A \cup C>0.90$ [47]. In addition, the predictive

\section{RESULTS}

Fall history data, for the analysis of discriminant validity, was available could be collected only from in 295 subjects: 135 fallers (45\%) and 160 non-fallers (55\%). Table 1 reports mean scores and standard deviation for each balance measure as well as information on the use of walking aids in the overall sample and in fallers vs. non-fallers. We found a significant difference between fallers and non-fallers in the mean score of all clinical evaluations, while mean age and sex did not differ significantly. Table 2 reports descriptive statistics for each item score and total score of the original 8-item Brief-BESTest in the whole sample.

\section{Structural validity}

\section{Analysis of the Brief-BESTest models}

Figure $1 \mathrm{~A}$ shows the standardized solution of the CFA for Model 1 that was fitted using all 8 items. We found $\chi^{2}$ value of $134.0(d f=20, p<0.001)$, with CFI of $0.78, T L I$ of 0.70 , RMSEA of 0.12 $(90 \%$ C.I. $=0.10-0.14)$ and SRMR above 0.09. Both CFI and TLI were below the cut-off value of 
2540.95 defined for a well-fitting model. In addition, the RMSEA value suggested that this model 255 exhibited a poor fit of the data.

\section{Internal consistency}

Cronbach's alpha was good for Brief-BESTest Models 1 (0.92) and 3 (0.92), but not for Model 2 ( 0.56 and 0.88 , respectively for static and dynamic balance factor). Coefficient omega was higher than 0.80 only for Model 3, while Model $1(0.75)$ and Model 2 ( 0.71 and 0.61 , respectively for 
275 static and dynamic balance factor) showed a lower coefficient, thus suggesting that only Model 3 276 had good internal consistency.

277 The total score of the Brief-BESTest needs to be weighted considering the loading coefficient of

each item. Therefore, scores were adjusted to yield a uniform score range 0-24 for all three models, where 0 represents severe impairment and 24 no balance impairment. Below are the weighted total score equations used to estimate Models 2 and 3 :

Brief-BESTest $($ Model 2$)=$ $(0.860504 *$ item 1$)+(0.914286 *$ item 2$)+(1.089076 *$ item 3$)+(1.048739 *$ item 4$)+(1.021849 *$ item5 $)+$ $(0.994958 *$ item6)+(1.008438*item7)+(1.062185*item8)

Brief-BESTest $($ Model 3) $=$ $(0.963107 *$ item 2$)+(1.133981 *$ item3 $)+(1.118447 *$ item4 $)+(1.21165 *$ item5 $)+(1.165049 *$ item6)+ (1.165049*item7)+(1.242718*item8)

\section{Convergent validity}

The relationship of the total score estimated by the three different models of Brief-BESTest and the $A B C$ 5-levels scale was rho $=0.62(95 \%$ C.I. $=0.55-0.70)$ for Model 1, rho $=0.61(95 \%$ C.I. $=$ 0.54-0.69) for Model 2 and rho $=0.61(95 \%$ C.I. $=0.54-0.69)$ for Model 3. No significant $(p=0.85)$ difference was found between the three Spearman correlation coefficients.

\section{Discriminant validity}

Figure 2 shows the ROC curve plotted to assess the ability of the three models of Brief-BESTest to discriminate between patients with vs. without a history of falls. Table 4 reports the discrimination parameters (cut-off scores) for Models 1, 2 and 3 and for the simple balance tests 
293 (OLS, TUG test and FR). The AUC was $0.72(95 \%$ C.I. $=0.66-0.78)$ for all three models. Model 3 294 showed superior sensitivity, specificity and likelihood ratios compared to the other two 295 models. The other simple balance tests (OLS, TUG test and FR) did not reach the AUC value of 2960.70 , i.e. the cut-off value required to distinguish between fallers and non-fallers. In addition, 12 3297 their AUCs were lower than those of the Brief-BESTest models.

\section{DISCUSSION}

The main purpose of this study was to compare, in a large group of patients with balance disorders, the structural, convergent and discriminant validity of three different models of the Brief-BESTest. The Brief-BESTest, in particular Model 3, was found to be unidimensional and to have a good convergent validity with other measures of balance confidence. In addition, the Brief-BESTest confirmed its ability to distinguish subjects with a history of falling from those without a history of falling, in contrast to other simple balance tests.

\section{Structural validity}

CFA showed that measurement properties of the original Brief-BESTest scale (Model 1) [13] little fitted our data; none of CFA performance indices reached satisfactory values. As suggested in a previous study [14], the original Brief-BESTest can be improved by making the following modifications: a) removing item 1; b) covarying errors between items 3 and 4 and between items 5 and 6 ; c) using an appropriate weighting method for the calculation of the total score. The internal structure of the scale can, in fact, be improved by removing item 1 rather than by increasing the number of factors as proposed earlier [19]. The analysis of structural validity 
315 prompted two main considerations. First, item 1 does not belong to the same construct as the 316 other items. This finding, in line with previous studies $[14,19]$, is also supported by the fact that 317 "lift a leg to the side of the body" (item 1) could reflect a general reduction in strength rather ${ }_{1} 318$ than a decreased ability to maintain static balance. Second, the Brief-BESTest is unidimensional 12

because no advantage in terms of fitting performance was found when more than one factor was taken into consideration. In other words, our study confirmed that the Brief-BESTest is not able to measure multiple dimensions of balance as claimed by [13]. The Brief-BESTest items include all subsections covered by the BESTest, but this does not mean that the two scales have the same capability to measure the different aspects underlying postural control. In accordance with other authors, one could object that a unidimensional tool is a poor representation of the balance concept, which by definition is multidimensional. We agree with this objection and believe that the Brief-BESTest can assess only certain aspects of dynamic balance. It neglects static components of balance such as those measured by the "Romberg test". On the other hand, some aspects of balance considered independent in animal models [48], such as walking and maintenance of upright position, could be actually considered aswell belonging to the same construct in humans. In fact, balance control and locomotion are interdependent at many different levels of the central nervous system and these functions share some common principles of organization $[49,50]$. Furthermore, previous studies have reported that the ability to maintain upright stance could be related to walking $[51,52,53]$ in patients affected by balance disorders. Hence, in these patients it might be misleading for a clinical scale to investigate balance and walking as two separate factors, as also suggested by recent recommendations [54].

\section{Internal consistency}


337 Despite the large consensus in the psychometric literature that coefficient omega should be used 338 when scales are not congeneric and the assumptions of Cronbach's alpha are not met [41], no 339 previous study has reported omega values for the Brief-BESTest. This is the first study to report both the alpha and the omega coefficients. Based on the latter values, only Model 3 achieved good internal validity. On the contrary, Cronbach's alpha values were found to be good for both Model 1 and 3. Our values of alpha are similar to those reported by [13], and to other studies in both orthopaedic [55] and neurological patients [56]. It is well known that Cronbach's alpha is a function of the number of items. In this regard, it is interesting to note that Model 3, despite its lower number of items, reaches a higher value of internal consistency than the other models. This should denote a superior internal consistency of Model 3.

The discrepancy between the results for Cronbach's alpha and those for coefficient omega can be explained by the fact that the former has been frequently demonstrated to attain quite high values even when the items are measuring different latent variables [57]. On the contrary, the coefficient omega is able to highlight the presence of items that do not belong to the same latent variable. As for the Brief-BESTest, the low values of coefficient omega found for Model 1 could be due to the presence of item 1, which, as highlighted by CFA, seems not to belong to the same construct as the other items.

\section{Convergent validity}

The three models compared in this study exhibit an equivalent moderate convergent validity (Spearman's rho $=0.61$ ) with the ABC 5-levels scale. This finding confirms previous studies in which the Brief-BESTest showed a moderate correlation with $A B C$ in specific populations, such as chronic obstructive pulmonary disease [15], stroke [11] and cancer survivors patients [58]. This is 
359 not surprising since it is well known that balance confidence is a consequence of balance 360 impairments [59].

\section{Discriminant validity}

The three Brief-BESTest models exhibited an equallyivalent and acceptable accuracy (AUC $=0.72$ ) of the Brief-BESTest in distinguishing patients with vs. without history of falls. However, our AUCs are lower than those of [17], who found in patients with Parkinson's disease AUC values of 0.82 , 0.86 and 0.84 respectively for the Brief-BESTest, Mini-BESTest and BESTest, thus indicating a moderate accuracy of the three scales in recognising a history of falls. Likely, the small difference is due to the heterogeneity of our patients. It We cannot be excluded that studying separate disease populations might improve the discriminant validity.

In accordance line with previous studies, we confirm that balance scales can discriminate between fallers and non-fallers, in contrast to single balance tests which have a we found a low level of accuracy in identifying fallers using only a single balance test $[11,60,61]$. Due to the heterogeneity of patients in our study, it is unlikely that a single test could accurately identify patients at risk of falls. This is in line with recommendations of [62] who suggested to use two or more clinical tests for an accurate evaluation of the various components of risk of falls in patients with Parkinson's disease. The limited association between single measures of balance and fall history could be partly explained bydue to the multifactorial nature of causes of fall.

\section{Study limitations}

Our study was based on a heterogeneous population sample of patients affected by different balance disorders that are representative of the spectrum of neurological diseases routinely 
381 observed in departments of rehabilitation, but may not be representative of other clinical

\section{Authors' contributions}

$X X$ and $X X$ contributed to the concept/idea/research design. $X X, X X$ and $X X$ contributed to the writing and data analysis. $X X$ and $X X$ provided data collection. $X X$ and $X X$ provided project management and study participants. XX and XX provided facilities/equipment and institutional 
403 liaisons. $X X$ and $X X$ contributed consultation in different phases of the study (including review of 404 manuscript before submission).

\section{Ethical Approval}

The Scientific Technical Committee of the XXXXXX approved this study with the following

15407 identification number: XXXX.

\section{Funding}

This research did not receive any specific grant from funding agencies in the public, commercial, or not-for-profit sectors.

\section{Conflict of Interest}

None declared.

\section{Bibliography}

[1] Geiger RA, Allen JB, O'Keefe J, Hicks RR. Balance and mobility following stroke: effects of physical therapy interventions with and without biofeedback/forceplate training. Phys Ther 2001;81(4):995-1005. PubMed PMID: 11276182.

[2] Hyndman D, Ashburn A. People with stroke living in the community: Attention deficits, balance, ADL ability and falls. Disabil Rehabil 2003;25(15):817-22. PubMed PMID: 12851091. 
421 [3] Horlings CG, Van Engelen BG, Allum JH, Bloem BR. A weak balance: the contribution of muscle 422 weakness to postural instability and falls. Nat Rev Neurol. 2008;4(9):504. doi:

$423 \quad 10.1038 /$ ncpneuro0886.

[4] Sturnieks DL, St George R, Lord SR. Balance disorders in the elderly. Neurophysiol Clin 2008;38(6):467-478. doi: 10.1016/j.neucli.2008.09.001.

[5] Mancini M, Horak FB. The relevance of clinical balance assessment tools to differentiate balance deficits. Eur J Phys Rehabil Med 2010;46:239. PubMed PMID: 20485226.

[6] McGinnis PQ, Hack LM, Nixon-Cave K, Michlovitz SL. Factors that influence the clinical decision making of physical therapists in choosing a balance assessment approach. Phys Ther 2009;89:233. doi: 10.2522/ptj.20080131.

[7] Sibley KM, Straus SE, Inness EL, Salbach NM, Jaglal SB. Balance assessment practices and use of standardized balance measures among Ontario physical therapists. Phys Ther 2011;91:1583. doi: 10.2522/ptj.20110063.

[8] Horak FB, Wrisley DM, Frank J. The Balance Evaluation Systems Test (BESTest) to differentiate balance deficits. Phys Ther 2009;89:484-498. doi: 10.2522/ptj.20080071.

[9] Jacobs JV, Horak FB, Tran VK, Nutt JG. Multiple balance tests improve the assessment of postural stability in subjects with Parkinson's disease. J Neurol Neurosurg Psychiatry 2006;1;77(3):322-6. PubMed PMID: 16484639.

[10] Jacobs JV, Earhart GM, McNeely ME. Can postural instability tests improve the prediction of future falls in people with Parkinson's disease beyond knowing existing fall history? J Neurol 2016;263(1):133-9. doi: 10.1007/s00415-015-7950-x. 
442 [11] Tsang CS, Liao LR, Chung RC, Pang MY. Psychometric properties of the Mini-Balance $443 \quad$ Evaluation Systems Test (Mini-BESTest) in community-dwelling individuals with chronic $444 \quad$ stroke. Phys Ther 2013;93:1102-15. doi: 10.2522/ptj.20120454.

[12] Franchignoni F, Horak F, Godi M, Nardone A, Giordano A. Using psychometric techniques to improve the Balance Evaluation Systems Test: the Mini-BESTest. J Rehabil Med 2010;42:323331. doi: 10.2340/16501977-0537.

[13] Padgett PK, Jacobs JV and Kasser SL. Is the BESTest at its best? A suggested brief version based on interrater reliability, validity, internal consistency, and theoretical construct. Phys Ther 2012;92:1197-1207. doi: 10.2522/ptj.20120056.

[14] Bravini E, Nardone A, Godi M, Guglielmetti S, Franchignoni F, Giordano A. Does the BriefBESTest meet classical test theory and Rasch analysis requirements for balance assessment in people with neurological disorders? Phys Ther 2016;96:1610-1619. PubMed PMID: 27103223.

[15] Jácome C, Cruz J, Oliveira A, Marques A. Validity, reliability, and ability to identify fall status of the Berg Balance Scale, BESTest, Mini-BESTest, and Brief-BESTest in patients with COPD. Phys Ther 2016;96(11):1807-1815. doi: 10.2522/ptj.20150391.

[16] Leddy AL, Crowner BE, Earhart GM. Utility of the Mini-BESTest, BESTest, and BESTest sections for balance assessments in individuals with Parkinson disease. J Neurol Phys Ther 2011;35:90-97. doi: 10.1097/NPT.0b013e31821a620c.

[17] Duncan RP, Leddy AL, Cavanaugh JT, Dibble LE, Ellis TD, Fors MP, Foreman KB, Earhart GM. Comparative utility of the BESTest, Mini-BESTest, and Brief-BESTest for predicting falls in 
463 individuals with Parkinson disease: a cohort study. Phys Ther 2013;93:542-550. doi: $464 \quad 10.2522 / p t j .20120302$.

[18] O’Hoski S, Winship B, Herridge L, Agha T, Brooks D, Beauchamp MK, Sibley KM. Increasing the clinical utility of the BESTest, Mini-BESTest, and Brief-BESTest: normative values in Canadian adults who are healthy and aged 50 years or older. Phys Ther 2014;94:334-342. doi: 10.2522/ptj.20130104.

[19] Franchignoni F, Giordano A. On "Is the BESTest at its best?...." Padgett PK, Jacobs JV, Kasser SL. Phys Ther 2012;92:1197-1207. Phys Ther 2012;92(9):1236-7. doi: 10.2522/ptj.2012.92.9.1236.

[20] Marques A, Almeida S, Carvalho J, Cruz J, Oliveira A, Jácome C. Reliability, Validity, and Ability to Identify Fall Status of the Balance Evaluation Systems Test, Mini-Balance Evaluation Systems Test, and Brief-Balance Evaluation Systems Test in Older People Living in the Community. Arch Phys Med Rehabil 2016;97:2166-2173. doi: 10.1016/j.apmr.2016.07.011.

[21] McArdle JJ. Current directions in structural factor analysis. Curr Dir Psychol Sci 1996;5:11-18.

[22] Norman GR, Streiner DL. PMPH-USA. PDQ statistics; 1st edition, 2003.

[23] Jansen AC, van Aalst-Cohen ES, Hutten BA, Büller HR, Kastelein JJ, Prins MH. Guidelines were developed for data collection from medical records for use in retrospective analyses. J Clin Epidemiol 2005;58(3):269-274. doi: 10.1016/j.jclinepi.2004.07.006.

[24] Jernigan SD, Pohl PS, Mahnken JD, Kluding PM. Diagnostic accuracy of fall risk assessment tools in people with diabetic peripheral neuropathy. Phys Ther 2012;92:1461-1470. doi: 10.2522/ptj.20120070. 
484 [25] Lin MR, Hwang HF, Hu MH, Wu HDI, Wang YW, Huang FC. Psychometric comparisons of the 485 timed up and go, one-leg stand, functional reach, and Tinetti balance measures in 486 community-dwelling older people. J Am Geriatr Soc 2004;52:1343-1348. doi: 10.1111/j.1532$1487 \quad 5415.2004 .52366 . x$.

[26] Vellas BJ, Wayne SJ, Romero L, Baumgartner RN, Rubenstein LZ, Garry PJ. One-leg balance is an important predictor of injurious falls in older persons. J Am Geriatr Soc 1997;45:735-738. PubMed PMID: 9180669.

[27] Sebastião E, Sandroff BM, Learmonth YC, Motl RW. Validity of the timed up and go test as a measure of functional mobility in persons with multiple sclerosis. Arch Phys Med Rehabil 2016;97:1072-1077. doi: 10.1016/j.apmr.2015.12.031.

[28] Podsiadlo D, Richardson S. The timed 'Up \& Go': A test of basic functional mobility for frail elderly persons. J Am Geriatr Soc 1991;39:142-148. PubMed PMID: 1991946.

[29] Franchignoni F, Tesio L, Martino M, Ricupero C. Reliability of four simple, quantitative tests of balance and mobility in healthy elderly females. Aging Clin Exp Res 1998;10:26-31. PubMed PMID: 9589748.

[30] Duncan PW, Weiner DK, Chandler J, Studenski S. Functional reach: a new clinical measure of balance. J Gerontol 1990;45(6):M192-7. PubMed PMID: 2229941.

[31] Powell LE, Myers AM. The activities-specific balance confidence (ABC) scale. J Gerontol A Biol Sci Med Sci 1995;50(1):M28-M34. PubMed PMID: 7814786.

[32] Franchignoni F, Giordano A, Ronconi G, Rabini A, Ferriero G. Rasch validation of the Activities-specific Balance Confidence Scale and its short versions in patients with Parkinson's disease. J Rehabil Med 2014;46:532-539. doi: 10.2340/16501977-1808. 
506 [33] Atkinson TM, Rosenfeld BD, Sit L, Mendoza TR, Fruscione M, Lavene D, Shaw M, Li Y, Hay J, 507 Cleeland CS, Scher HI, Breitbart WS, Basch E. Using confirmatory factor analysis to evaluate 508 construct validity of the Brief Pain Inventory (BPI). J Pain Symptom Manage 2011;41(3):558-

[34] Bentler PM. Comparative fit indexes in structural models. Psychol Bull 1990;107(2):238-46. PubMed PMID: 2320703.

[35] Browne MW, Cudeck R. Alternative ways of assessing model fit. In: Bollen KA, Long JS, editors. Testing Structural Equation Models. Newbury Park: Sage 1993;136-62.

[36] Hu LT, Bentler P. Cutoff criteria for fit indices in covariance structure analysis: conventional criteria versus new alternatives. Struct Equ Model Multidiscip J 1999;6:1-55. doi: 10.1080/10705519909540118.

[37] DiStefano C, Zhu M, Mindrila D. Understanding and using factor scores: Considerations for the applied researcher. PARE 2009;14(20):1-11.

[38] Schönberger M, Ponsford J, Olver J, Ponsford, M. A longitudinal study of family functioning after TBI and relatives' emotional status. Neuropsychol Rehabil 2010;20:813-829. doi: 10.1080/09602011003620077.

[39] Hancock GR, Mueller RO. Rethinking construct reliability within latent variable systems. Structural equation modeling: Present and future-A Festschrift in honor of Karl Jöreskog. Lincolnwood, IL: Scientific Software International 2001;195-216.

[40] Cronbach $\sqcup$. Coefficient alpha and the internal structure of tests. Psychometrika 1951;16(3):297-334. PubMed PMID: 8449658. 
527 [41] Dunn TJ, Baguley T, Brunsden V. From alpha to omega: a practical solution to the pervasive 528 problem of internal consistency estimation. Br J Psychol 2014;105:399-412. doi:

$529 \quad$ 10.1111/bjop.12046.

[42] Opheim A, Jahnsen R, Olsson E, Stanghelle JK. Balance in relation to walking deterioration in adults with spastic bilateral cerebral palsy. Phys Ther 2012;92(2):279-88. doi: 10.2522/ptj.20100432.

[43] Curtze C, Nutt JG, Carlson-Kuhta P, Mancini M, Horak FB. Objective gait and balance impairments relate to balance confidence and perceived mobility in people with Parkinson disease. Phys Ther 2016;96(11):1734-1743. PubMed PMID: 27149959.

[44] Rand D. Mobility, balance and balance confidence - correlations with daily living of individuals with and without mild proprioception deficits post-stroke. NeuroRehabilitation 2018;43(2):219-226. doi: 10.3233/NRE-172398.

[45] Salbach NM, Mayo NE, Hanley JA, Richards CL, Wood-Dauphinee S. Psychometric evaluation of the original and Canadian French version of the activities-specific balance confidence scale among people with stroke. Arch Phys Med Rehabil 2006;87(12):1597-604. PubMed PMID: 17141639.

[46] Cohen, J. Statistical power analysis for the behavioral sciences. 2nd edition, 1988.

[47] Akobeng AK. Understanding diagnostic tests 3: receiver operating characteristic curves. Acta Paediatr 2007;96:664-647. doi: 10.1111/j.1651-2227.2006.00178.x.

[48] Hodgson JA, Roy RR, de Leon R, Dobkin B, Edgerton VR. Can the mammalian lumbar spinal cord learn a motor task? Med Sci Sports Exerc 1994;26:1491-1497. PubMed PMID: 7869884. 
548 [49] Grasso R, Zago M, Lacquaniti F. Interactions between posture and locomotion: motor 549 patterns in humans walking with bent posture versus erect posture. J Neurophysiol $550 \quad$ 2000;83:288-300. doi: 10.1152/jn.2000.83.1.288.

[50] Massion J. Movement, posture and equilibrium: interaction and coordination. Prog Neurobiol 1992;38(1):35-56. Review. PubMed PMID: 1736324.

[51] Giardini M, Nardone A, Godi M, Guglielmetti S, Arcolin I, Pisano F, Schieppati M. Instrumental or physical-exercise rehabilitation of balance improves both balance and gait in Parkinson's disease. Neural Plast 2018;2018:5614242. doi: 10.1155/2018/5614242.

[52] Nardone A, Godi M, Grasso M, Guglielmetti S, Schieppati M. Stabilometry is a predictor of gait performance in chronic hemiparetic stroke patients. Gait Posture 2009;30(1):5-10. doi: 10.1016/j.gaitpost.2009.02.006.

[53] Morlino P, Balbi B, Guglielmetti S, Giardini M, Grasso M, Giordano C, Schieppati M, Nardone A. Gait abnormalities of COPD are not directly related to respiratory function. Gait Posture 2017;58:352-357. doi: 10.1016/j.gaitpost.2017.08.020.

[54] Bloem BR, Marinus J, Almeida Q, Dibble L, Nieuwboer A, Post B, Ruzicka E, Goetz C, Stebbins G, Martinez-Martin P, Schrag A; Movement Disorders Society Rating Scales Committee. Measurement instruments to assess posture, gait, and balance in Parkinson's disease: Critique and recommendations. Mov Disord 2016;31(9):1342-55. doi: 10.1002/mds.26572.

[55] Chan AC, Pang MY. Assessing balance function in patients with total knee arthroplasty. Phys Ther 2015;95(10):1397-407. doi: 10.2522/ptj.20140486. 
568 [56] Huang M, Pang MY. Psychometric properties of Brief-Balance Evaluation Systems Test (Brief569 BESTest) in evaluating balance performance in individuals with chronic stroke. Brain Behav $570 \quad$ 2017;7(3):e00649. doi: 10.1002/brb3.649.

[57] Revelle W, Zinbarg RE. Coefficients alpha, beta, omega, and the glb: Comments on Sijtsma. Psychometrika 2009;74(1):145. doi:10.1007/s11336-008-9102-z.

[58] Huang MH, Miller K, Smith K, Fredrickson K, Shilling T. Reliability, validity, and minimal detectable change of Balance Evaluation Systems Test and its short versions in older cancer survivors: a pilot study. J Geriatr Phys Ther 2016;39(2):58-63. doi: 10.1519/JPT.0000000000000047.

[59] Mak MK, Pang MY. Balance confidence and functional mobility are independently associated with falls in people with Parkinson's disease. J Neurol 2009;256:742-749. doi: 10.1007/s00415-009-5007-8.

[60] Cameron M, Mazumder R, Murchison C, King L. Mini Balance Evaluation Systems Test in people with multiple sclerosis: reflects imbalance but may not predict falls. Gait Posture 2014;39(1):669. doi: 10.1016/j.gaitpost.2013.08.009.

[61] Mak MK, Auyeung MM. The mini-BESTest can predict parkinsonian recurrent fallers: a 6month prospective study. J Rehabil Med 2013;45:565-571. doi: 10.2340/16501977-1144.

[62] Dibble LE, Christensen J, Ballard DJ, Foreman KB. Diagnosis of fall risk in Parkinson disease: an analysis of individual and collective clinical balance test interpretation. Phys Ther 2008;88:323-332. doi: 10.2522/ptj.20070082. 


\section{Table 1}

590 Demographic data and scores on balance measures for the entire sample, and fallers vs. non-

591 fallers.

\begin{tabular}{lcccc}
\hline & $\begin{array}{c}\text { Entire Total Sample } \\
\text { (N=416) }\end{array}$ & Fallers (N=135) & Non-fallers (N=160) & \multirow{2}{*}{$p$} \\
\cline { 2 - 4 } & $\mathrm{N} \%$ & $\mathrm{~N} \%$ & $\mathrm{~N} \%$ & \\
\hline Sex (M/F) & $55 / 45$ & $51 / 49$ & $58 / 42$ & $.23^{\mathrm{a}}$ \\
Walking Aid (no/yes) & $54 / 46$ & $47 / 53$ & $68 / 32$ & $<.001^{\mathrm{a}}$ \\
\cline { 2 - 4 } & Mean (SD) & Mean (SD) & Mean (SD) & \\
Age (y) & $66.5(14.2)$ & $66.3(13.4)$ & $64.4(14.8)$ & $.28^{\mathrm{b}}$ \\
OLS mean (s) & $4.2(6.3)$ & $3.3(5.0)$ & $6.9(7.5)$ & $<.001^{\mathrm{b}}$ \\
TUG test (s) & $17.6(15.3)$ & $20.6(20.3)$ & $13.3(9.5)$ & $<.001^{\mathrm{b}}$ \\
Functional Reach (cm) & $18.6(9.7)$ & $16.5(9.6)$ & $20.5(9.8)$ & $<.01^{\mathrm{b}}$ \\
Total score BBT & $8.9(6.4)$ & $7.3(5.1)$ & $11.8(6.9)$ & $<.001^{\mathrm{b}}$ \\
Total score ABC 5-levels & $29.6(16.8)$ & $26.0(15.0)$ & $36.2(17.1)$ & $<.001^{\mathrm{b}}$ \\
\hline
\end{tabular}

The total sample comprises all patients, i.e. those in whom a fall history was collected (the two subgroups fallers/non-fallers) as well as those in whom a fall history was not collected due to acute stroke event $(n=79)$ or failure to complete the questionnaire $(n=42)$, as this is a

retrospective study. Participants were classified as fallers if they reported $\mathbf{1} \mathbf{2}$ or more falls in the last 6 months.

SD, Standard Deviation; M, Male; F, Female; OLS, One Leg Stance; TUG test, Timed Up and Go test; BBT, Brief-BESTest; ABC 5-levels, Activities-specific Balance Confidence scale 5-levels of rating.

p-value was computed between fallers and non-fallers.

$\mathrm{a}=\chi^{2}$ test.

$\mathrm{b}=$ Mann-Whitney U-test. 
Table 2

Details on each single item and total score of the original Brief-BESTest (Model 1 ) in the whole sample (N

\begin{tabular}{lcccccccc}
\hline & Median & $\begin{array}{c}25 \% \\
\text { percentile }\end{array}$ & $\begin{array}{c}75 \% \\
\text { percentile }\end{array}$ & Skewness & Kurtosis & $\begin{array}{c}\text { Min score } \\
(\%)\end{array}$ & $\begin{array}{c}\text { Max score } \\
(\%)\end{array}$ & $\begin{array}{c}\text { Missing } \\
\text { data (\%) }\end{array}$ \\
\hline Item 1 & 1 & 0 & 2 & 0.39 & -1.20 & 42.51 & 7.73 & 0.40 \\
Item 2 & 2 & 1 & 2 & -0.47 & -0.13 & 9.42 & 10.39 & 0.40 \\
Item 3 & 1 & 0 & 1 & 0.93 & -0.15 & 46.62 & 8.70 & 0.00 \\
Item 4 & 1 & 0 & 1 & 0.89 & -0.25 & 44.69 & 9.66 & 0.00 \\
Item 5 & 1 & 0 & 2 & 0.59 & -1.19 & 48.07 & 17.15 & 0.00 \\
Item 6 & 1 & 0 & 2 & 0.53 & -1.26 & 45.89 & 18.84 & 0.00 \\
Item 7 & 1 & 0 & 2 & 0.66 & -0.99 & 43.96 & 16.91 & 0.00 \\
Item 8 & 2 & 0 & 2 & 0.07 & -1.54 & 36.47 & 23.43 & 0.00 \\
\hline Total score & 8 & 4 & 13 & 0.54 & -0.69 & 6.00 & 8.00 & \\
\hline
\end{tabular}

Item 1 - Hip/Trunk Lateral Strength; item 2 - Functional Reach Forward; item 3 and 4 - One Leg Stance, Left and Right; item 5 and 6 - Compensatory Stepping- Lateral, Left and Right; item 7 stand on a foam surface; 8 - Timed Up and Go test. 


\section{Table 3}

619 Summary of fit statistics of the specified models $(N=416)$

\begin{tabular}{|c|c|c|c|c|c|c|}
\hline Models & $\chi^{2}$ & df & RMSEA (90\% C.I.) & $\mathrm{CFI}$ & TLI & SRMR \\
\hline $\begin{array}{l}\text { Model } 1 \\
\text { (Padgett et al., 2012) }\end{array}$ & 134.0 & 20 & $0.12(0.10-0.14)$ & 0.78 & 0.70 & 0.09 \\
\hline $\begin{array}{l}\text { Model } 2 \\
\text { (adapted from Franchignoni \& Giordano, } \\
\text { 2012) }\end{array}$ & 60.3 & 18 & $0.08(0.06-0.10)$ & 0.92 & 0.88 & 0.05 \\
\hline $\begin{array}{l}\text { Model } 3 \\
\text { (adapted from Bravini et al., 2016) }\end{array}$ & 26.2 & 12 & $0.05(0.03-0.08)$ & 0.97 & 0.95 & 0.03 \\
\hline Comparison of factor models & \multicolumn{6}{|c|}{ Significant difference between models ${ }^{a}$} \\
\hline Model 1 vs. Model 2 & \multicolumn{6}{|c|}{$p<0.001$} \\
\hline Model 2 vs. Model 3 & \multicolumn{6}{|c|}{$p<0.001$} \\
\hline Model 3 vs. Model 1 & \multicolumn{6}{|c|}{$p<0.001$} \\
\hline
\end{tabular}

$621 \mathrm{df}$, degrees of freedom; RMSEA, Root Mean-Square Error of Approximation; C.I., Confidence 33

Interval; CFI, Comparative Fit Index; TLI, Tucker-Lewis Index; SRMSR, Standardized Root Mean

Square Residual.

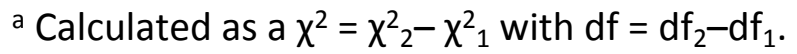


627 Table 4

628 Ability of the Brief-BESTest Models 1, 2 and 3 to discriminate fallers from non-fallers compared to

629 other measures of balance (OLS, TUG test, Functional Reach and ABC 5-levels) $(\mathbf{N}=\mathbf{2 9 5})$.

\begin{tabular}{lcccccc}
\hline Classification & $\begin{array}{c}\text { Brief-BESTest } \\
\text { Model 1 }\end{array}$ & $\begin{array}{c}\text { Brief-BESTest } \\
\text { Model 2 }\end{array}$ & $\begin{array}{c}\text { Brief-BESTest } \\
\text { Model 3 }\end{array}$ & OLS & TUG test & FR \\
\hline Cut-off score & 8 & 8 & 7 & 2 & 12 & 19 \\
AUC (95\% C.I.) & 0.72 & 0.72 & 0.72 & 0.63 & 0.62 & 0.61 \\
Sensitivity & $(0.66-0.78)$ & $(0.66-0.78)$ & $(0.66-0.78)$ & $(0.55-0.70)$ & $(0.56-0.68)$ & $(0.52-0.69)$ \\
Specificity & $74 \%$ & $72 \%$ & $74 \%$ & $63 \%$ & $68 \%$ & $67 \%$ \\
LR+ & $54 \%$ & $58 \%$ & $58 \%$ & $55 \%$ & $53 \%$ & $49 \%$ \\
LR- & 1.61 & 1.72 & 1.76 & 1.42 & 1.45 & 1.33 \\
Correctly Classified & $65 \%$ & 6.47 & 0.45 & 0.66 & 0.60 & 0.67 \\
\hline
\end{tabular}

OLS, One Leg Stance; TUG test, Timed Up and Go test; FR, Functional Reach; AUC, Area Under the Curve; C.I., Confidence Interval; LR+, positive Likelihood Ratio; LR-, negative Likelihood Ratio. 
635 Appendix 1

636 Items and factors of the three models of Brief-BESTest.

\begin{tabular}{l|c|c|c}
\hline $\begin{array}{l}\text { Model item } \\
\text { (Scoring 0-3 per item) }\end{array}$ & Model 1 & Model 2 & Model 3 \\
\hline Item 1: Hip/Trunk Lateral Strength & & Static Balance & \\
$\begin{array}{l}\text { Item 2: Functional Reach Forward } \\
\text { Item 3: Stand on One Leg-Left }\end{array}$ & & \\
Item 4: Stand on One Leg-Right & Dynamic Balance & & \multirow{2}{*}{ Dynamic Balance } \\
Item 5: Compensatory Stepping-Lateral, Left & & Dynamic Balance & \\
Item 6: Compensatory Stepping-Lateral, Right & & & \\
Item 7: Stand on foam surface with Eyes Closed & & $\begin{array}{c}0-24 \\
\text { (Static 0-5; } \\
\text { Item 8: Timed Up and Go test }\end{array}$ & \\
\hline Total score & & $0-24$ & $0-24$ \\
\hline
\end{tabular}


1 Is the Brief-BESTest brief enough? Suggested modifications based on structural validity and

2 internal consistency

3 Marco Godi a, Marica Giardini ${ }^{a}{ }^{*}$, Ilaria Arcolin a, Simona Ferrante ${ }^{\text {b }}$, Antonio Nardone a,c,

4 Stefano Corna a , Roberto Colombo ${ }^{a}$

5

6 Author affiliation:

$7 \quad$ astituti Clinici Scientifici Maugeri IRCCS, Italy

8 b Neuroengineering and Medical Robotics Laboratory, Politecnico di Milano, Italy

9 c Department of Clinical, Surgical, Diagnostic and Pediatric Sciences, University of Pavia, Italy 10

$11{ }^{*}$ Corresponding author: Marica Giardini.

12 Istituti Clinici Scientifici Maugeri IRCCS,

13 Via per Revislate 13, Veruno 28010, Italy.

14 E-mail address: marica.giardini@icsmaugeri.it

15 Ph: +390322 884905 


\section{ABSTRACT}

Background: The Brief Balance Evaluation Systems Test (Brief-BESTest) could be a useful tool for still need to be clarified.

Objectives: To assess the structural validity, convergent validity, discriminant validity and internal consistency of the Brief-BESTest in neurological patients.

Design: Cross-sectional.

Methods: Data were from 416 patients with neurological disease and related balance disorders. Patients were assessed with the 5-levels Activities-Specific Balance Confidence Scale (ABC 5levels), Brief-BESTest, some simple balance tests, i.e. One-Leg Stance (OLS), Timed Up and Go (TUG) test, Functional Reach (FR), simple balance tests and a fall history questionnaire. Three models of Brief-BESTest models were examined through confirmatory factor analysis (CFA) and the following indices calculated: Comparative Fit Index (CFI), Tucker-Lewis Index (TLI), Root Mean Square Error of Approximation (RMSEA). Convergent validity was assessed by calculating the correlation between Brief-BESTest and ABC 5-levels total scores. Receiver operating characteristics (ROC) assessed the ability of each model to differentiate between people with vs. without falls. Internal consistency was measured by Cronbach's alpha and coefficient omega.

Results: CFA showed Model $3(\mathrm{CFI}=0.97, \mathrm{TLI}=0.95, \mathrm{RMSEA}=0.05)$, with item 1 removed and error covariance between items 3-4 and between items 5-6, to have a significantly better structure than Models 1 and $2(p<0.001)$. The correlation between Brief-BESTest and ABC 5-levels was 0.61 (Spearman's rho) for all three models. Area Under the Curve (AUC) of ROC was showed an acceptable accuracy $(\mathbf{0 . 7 2})$ in distinguishing patients with vs. without history of falls $(95 \%$ C.I. $=0.66-0.78$ ) for all models, and superior to AUCs of other simple balance tests (OLS, TUG test, 
45 FR). Cronbach's alpha was good for Brief-BESTest Models 1 (0.92) and 3 (0.92), but omega was $46>0.80$ only for Model 3.

47 Limitations: Heterogeneous sample size was a heterogeneous population.

48 Conclusions: The Brief-BESTest, after some changes, shows good validity and internal

49 consistency in patients affected by different balance disorders, after applying some changes.

50

51 Contribution of the Paper:

52 - Although some psychometric characteristics of the Brief-BESTest have been examined in 53 previous studies, other properties such as validity still need to be clarified.

54 - This study shows that the Brief-BESTest has good validity and internal consistency in 55 patients affected by different balance disorders, after applying some changes: removal of item 1 56 and using an appropriate weighting method for the calculation of the total score.

- $\quad$ This study confirms the ability of the Brief-BESTest to distinguish between people with vs.

58 without history of falls, in contrast to other simple balance tests. Moreover, it highlights once 59 again the superiority of a clinical scale composed of several items compared to single-item 60 measures such as the TUG test and OLS. 


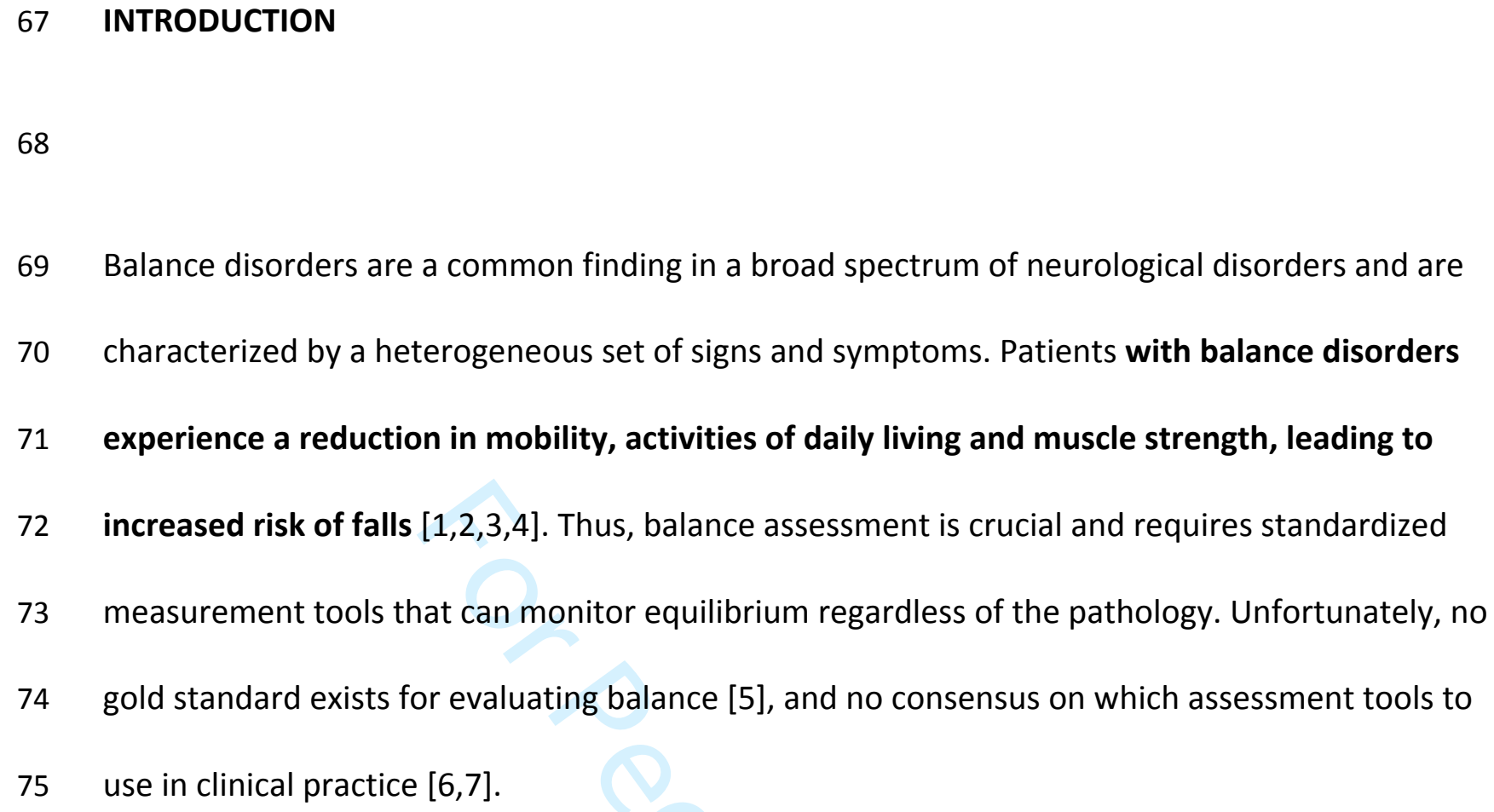

Balance disorders are a common finding in a broad spectrum of neurological disorders and are characterized by a heterogeneous set of signs and symptoms. Patients with balance disorders experience a reduction in mobility, activities of daily living and muscle strength, leading to increased risk of falls $[1,2,3,4]$. Thus, balance assessment is crucial and requires standardized measurement tools that can monitor equilibrium regardless of the pathology. Unfortunately, no gold standard exists for evaluating balance [5], and no consensus on which assessment tools to use in clinical practice $[6,7]$.

A variety of clinical measures has been developed to evaluate different aspects of balance. While simple balance tests such as the Timed Up and Go test, One Leg Stance, and Functional Reach provide accurate evaluation of a single task, they are not able to do not give information on multifactorial mechanisms related to postural stability [8]. On the contrary, balance scales which include multiple tasks can provide a more complete picture of balance control in all its complexity $[9,10,11]$.

One of the most recent balance scales is the BESTest, a 36-item scale developed to identify impairments in six balance control subsections, which it has been shown to be a valid and reliable tool [8]. However, one of its drawbacks is that it is time-consuming to administer [12]. For this reason, shorter versions have been proposed such as the Mini-BESTest [12] and the Brief-BESTest [13]. In particular, the Brief-BESTest, an 8-item version of the original scale, has demonstrated good to excellent psychometric properties $[8,13,14,15]$. It is less time-consuming [16] and more feasible than its parent scale in clinical settings [15], while it encompasses and should adequately evaluate all subsections of balance endorsed by the BESTest $[13,17,18]$. 
90 However, the latter hypothesis was rejected through exploratory factor analysis dismantled the

\section{latter hypothesis, demonstrating that the Brief-BESTest actually has at most two subsections,}

or dimensions [19]. Furthermore, Bravini et al. [14] showed by Rasch analysis that all items of the Brief-BESTest except for item 1 account for the same underlying theoretical construct and indicated that the Brief-BESTest should in fact be considered as unidimensional. Therefore, the authors suggested the adoption of a 7-item version of the test.

Although some psychometric characteristics of the Brief-BESTest, such as the internal consistency $[13,14]$, reliability $[14,17,20]$ and sensitivity to change $[14,20]$, have been investigated in previous studies, other properties still need to be clarified. In particular, the BriefBESTest structure has not yet been investigated with undergone confirmatory factor analysis (CFA). This statistical tool provides information on possible independent factors and can be very useful for developing shortened forms of an evaluating instrument [21,22]. Finally, the BriefBESTest seems to have good sensitivity and accuracy in identifying retrospectively people who have had at least one fall $[13,17]$. However, these findings are based only on small samples of patients with multiple sclerosis [13] or Parkinson's disease [17].

The We aimed in of the present study was to fill the existing knowledge gap by examining the structural validity, convergent validity and discriminant validity of the Brief-BESTest in a large group of patients with a variety of balance disorders. In particular, we hypothesized that:

1) among the three models of the Brief-BESTest presented in the literature $[13,14,19]$, the 7 -item version would be the one with the best structural validity;

2) in spite of its conciseness, the 7-item model [14] would have the same ability as the other two Brief-BESTest models to predict patients at risk of falls; discriminate between people with vs. without a history of falls; 
113 3) in discriminating between people with vs. without a history of falls, the Brief-BESTest would be 114 superior to other simple balance tests such as One Leg Stance, Timed Up and Go test and 115 Functional Reach.

\section{Participants}

This was an observational retrospective study conducted in a group of 416 patients affected by different neurological diseases: 186 females and 230 males; mean age $66.5 \pm 16.0$ years (mean \pm standard deviation) consecutively admitted for in-patient rehabilitation at the Istituti Clinici

Scientifici Maugeri IRCCS, Institute of Veruno (Novara, Italy) between February 2014 and April

2017. Patients' clinical and treatment data were extracted from the electronic medical record system and transferred to a specific database (Microsoft Excel). Patients were stratified into different groups according to their diagnosis: 118 with Parkinson's disease, 79 with acute stroke, 43 with sensorimotor polyneuropathy, 32 with cerebellar ataxia, 32 with diffuse encephalopathy, 31 with chronic stroke, 21 with multiple sclerosis, 19 with traumatic brain injury, 16 with vestibular disorder, 13 with neuromuscular disorders, 12 with central nervous system neoplasm. Inclusion criteria were: a) ability to maintain an upright position without support for at least 5 seconds; b) ability to understand the required motor tasks; c) no hip or knee replacement surgery within the previous 6 months. Exclusion criteria were: a) musculoskeletal injury limiting the ability to walk; b) any other serious cardio-respiratory problem. The study was carried out in conformity with the Declaration of Helsinki of the World 
135 Medical Association and the guidelines for retrospective studies [23]. The local scientific and 136 ethics committee approved the study.

\section{Assessment tools}

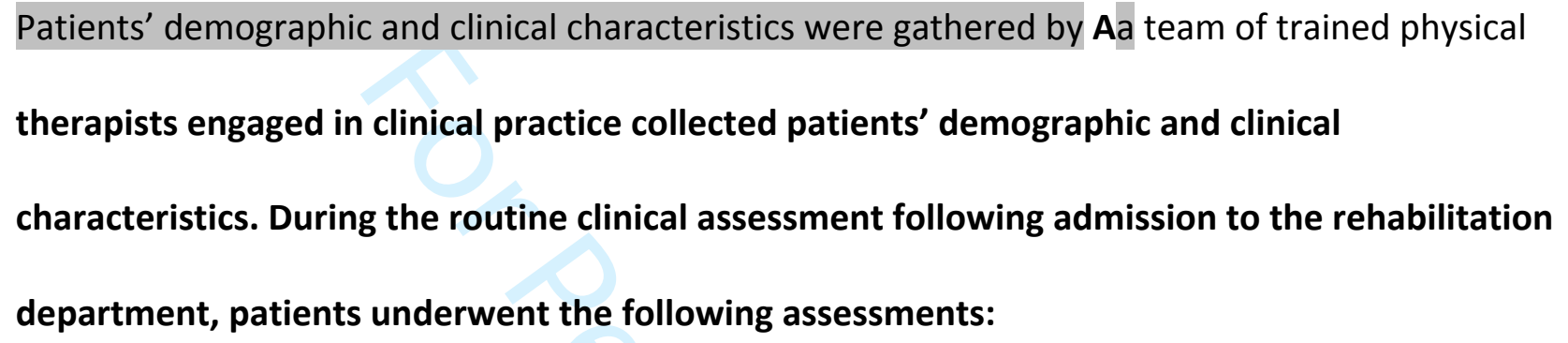

A history of falls over the past 6 months was obtained from patients at admission through patient interview. A fall was defined as an unintentional event in which any part of the body came into contact with the ground [10]. Patients who reported two or more falls in the defined period were classified as 'fallers' [24]. A fall history was not recorded taken in the case of for patients with acute stroke at the time of admission.

\section{- Brief-BESTest}

The Brief-BESTest is an 8-item scale with each item scored on a 4-level rating scale from 0 (severe balance impairment) to 3 (no balance impairment). Its items cover the six subsections of the original BESTest (biomechanical constraints, stability limits/verticality, anticipatory postural responses, postural responses, sensory orientation, stability in gait); the maximum total score is 24 [13]. The Brief-BESTest requires less time and equipment to administer than the BESTest and the Mini-BESTest; thus, the Brief-BESTest seems to be more feasible for clinical use [17]. 


\section{6 - Simple balance tests}

157 During administration of the Brief-BESTest, we recorded the time required by patients to 158 complete item 3 (left One Leg Stance), 4 (right One Leg Stance) and 8 (Timed Up and Go test) and

\section{Data analysis}

Descriptive statistics were used to describe mean demographic and balance performance characteristics of the entire sample and of the two smaller subgroups, classified as fallers and non-fallers. The analysis of discriminant validity was conducted only in these two subgroups,

\section{i.e. those patients who had a history of falls available. These values were also determined}

separately both for fallers and non-fallers. For each item of the Brief-BESTest we calculated: median value, spread ( $25^{\text {th }}-75^{\text {th }}$ percentiles), skewness and kurtosis. Floor and ceiling effects were analyzed by calculating the percentage of individuals obtaining the lowest and the highest score for each scale item. In order to detect differences in clinical characteristics between fallers 
178 and non-fallers, the Chi-square $\left(\chi^{2}\right)$ test was used for two parameters, sex and use of walking 179 aids, while the Mann-Whitney U-test was used for age, OLS, TUG test, FR, total score of Brief180 BESTest and total score of $A B C 5$-levels. Significance was set at $p<0.05$. All analyses were 181

\section{Structural validity}

Structural validity is usually assessed through CFA [33]. CFA assesses the degree to which responses on a $\mathrm{p} \times 1$ vector of observable random variables (the Brief-BESTest items) can be used to assign a value to one or more unobserved variable(s) (balance subsections). For this purpose, a specific mathematical model is identified and fitted to the patients' data.

The original model (Model 1) of the Brief-BESTest [13] comprises one factor with 8 independent items that contribute with the same weights to the total score. In the recent literature, two additional models of Brief-BESTest have been presented. Model 2 was designed based on [19]. It includes two factors: one named "static balance" that comprises items 1 and 2, and another called "dynamic balance" that contains items 3 to 8 . As demonstrated by the authors, items 5 and 6 showed local dependence, so Model 2 was designed allowing correlation between the errors of these items. In Model 3, was drawn up without item 1 was dropped, as suggested by [14]. In this 7-item model, the error of item 3 was allowed to correlate with that of item 4 and the error of item 5 with that of item 6.

For all models, the score of each item ranges from 0 to 3 . Then the total score was is obtained by multiplying the rated score by the coefficient fitted for each model (see below formula and supplementary data). In order to allow comparison of the score models, we adjusted the 
200 coefficients so have been adjusted as to maintain a total score in the range 0 to 24 . Appendix 1 201 summarizes the item structure of the three models and their total score.

Preliminary analysis conducted on Model 3 showed similar CFA results for patients who used a walking aid and those who did not. For this reason, we decided to consider the entire sample independently of the walking condition in creating our models.

We examined tThe structural validity of these three models (from here on Model 1, 2 and 3) was examined through CFA using Structural Equation Modeling (SEM). In view of the very low occurrence of missing data (maximum $0.4 \%$ ), cases with missing data were removed from the analysis. $\chi^{2}$ was used to identify whether the model fitted the data well. In addition, we assessed the models' goodness of fit using the following indices: Comparative Fit Index (CFI) [34], TuckerLewis Index (TLI), Root Mean Square Error of Approximation (RMSEA) [35] and the Standardized Root Mean Square Residual (SRMR) [34]. The criteria adopted to assess goodness of fit performance were: a) CFI and TLI values $\geq 0.95$; b) RMSEA value $<0.06$; and c) SRMR value $\leq 0.08$ [36].

The goodness of fit parameters of the three models were compared by computing the $\chi^{2}$ difference tests of each model pair, calculated as a $\chi^{2}=\chi^{2}{ }_{2}-\chi^{2}{ }_{1}$ with $\mathrm{df}=\mathrm{df}_{2}-\mathrm{df}_{1}$.

The standardized factor loadings of the models (i.e. the coefficients of the fitted model) were then transformed into weights that can be applied when scale scores for an individual are calculated. They were calculated with a non-refined method called "Weighted Sum Scores" [37]; these weights do not change the scale range [38].

\section{Internal consistency}

The internal consistency of the three Brief-BESTest models was measured by Cronbach's alpha 
and the coefficient omega for congeneric models [39]. Cronbach's alpha measures the extent to which the items consistently measure the same construct, with the value $\geq 0.80$ indicating good internal consistency [40]. The coefficient omega is the ratio of the true score variance and the total variance of the scale. Interpretation of coefficient omega is similar to that of Cronbach's alpha [41].

\section{Convergent validity}

We used the correlation between the three models of Brief-BESTest and the ABC 5-levels total score to assess the convergent validity. The $A B C$ scale led to rate rates the balance self-efficacy of patients [31]. This is associated with measures of balance [32], walking capacity [42], functional mobility [43], Activities of Daily Living performance [44], and perceived health status [45]. The choice to use the $A B C$ as a competitor an external criterion was also based on the need to avoid the comparisons ofng the three models with a scale that had items similar to the BriefBESTest. The correlation was assessed by means of Spearman's rho: coefficients $<0.30$ were interpreted as weak, those between 0.30 and 0.49 as moderate, and those $\geq 0.50$ as strong correlations [46].

\section{Discriminant validity}

To assess the ability of the three Brief-BESTest models to distinguish between 'fallers' and 'nonfallers', receiver operating characteristic (ROC) curves were computed, by plotting sensitivity on the $x$-axis against 1 - specificity on the $y$-axis. In our study, sensitivity was calculated as the number of patients correctly identified as 'fallers' and specificity as the number of patients 
244 correctly identified as 'non-fallers'. The optimal cut-off value was chosen on the ROC curve at the 245 point that jointly maximized sensitivity and specificity [47]. For each ROC, the area under the 246 curve (AUC) and the positive and negative likelihood ratios ( $L R+$ and $L R-)$ were computed to 247 maximize the cut off scores. Low, moderate and high accuracy of discrimination were defined 12 respectively as $A U C<0.70,0.70<A U C<0.90$, and $A U C>0.90$ [47]. In addition, the predictive performance of the three models was compared to that of the OLS, TUG test and FR tests by reporting the above described parameters and the percentage of correctly classified patients.

\section{RESULTS}

Fall history data, for the analysis of discriminant validity, was available could be collected only from in 295 subjects: 135 fallers (45\%) and 160 non-fallers (55\%). Table 1 reports mean scores and standard deviation for each balance measure as well as information on the use of walking aids in the overall sample and in fallers vs. non-fallers. We found a significant difference between fallers and non-fallers in the mean score of all clinical evaluations, while mean age and sex did not differ significantly. Table 2 reports descriptive statistics for each item score and total score of the original 8-item Brief-BESTest in the whole sample.

\section{Structural validity}

\section{Analysis of the Brief-BESTest models}

Figure $1 \mathrm{~A}$ shows the standardized solution of the CFA for Model 1 that was fitted using all 8 
265 items. We found $\chi^{2}$ value of 134.0 ( $\left.d f=20, p<0.001\right)$, with CFI of 0.78, TLI of 0.70, RMSEA of 0.12 $266(90 \%$ C.I. $=0.10-0.14)$ and SRMR above 0.09. Both CFI and TLI were below the cut-off value of 2670.95 defined for a well-fitting model. In addition, the RMSEA value suggested that this model 268 exhibited a poor fit of the data.

Model 2 (figure 1B) showed better values of goodness of fit with respect to the original model. In fact, Model 2 had $\chi^{2}$ of $60.3(d f=18, p<0.001)$, with CFI of 0.92 , TLI 0.88, RMSEA $0.08(90 \%$ C.I. = 0.06-0.10) and SRMR 0.05. However, only SRMR exhibited a value lower than the preselected well-fitting index value.

Figure $1 \mathrm{C}$ shows the CFA solution for Model 3. The results show a significantly better goodness of fit for this model $\left(\chi^{2}=26.2, d f=12, C F I=0.97, \mathrm{TLI}=0.95, \mathrm{RMSEA}=0.05(90 \%\right.$ C.I. $=0.03-0.08)$, SRMR $=0.03)$ than for Models 1 and 2. Comparison of Model $3\left(\chi^{2}=26.2\right)$ to Model $1\left(\chi^{2}=134.0\right)$ and Model $2\left(\chi^{2}=60.3\right)$ yielded a difference in $\chi^{2}$ value of 107.8 and 34.1 respectively and a difference of 6 degrees of freedom, suggesting that Model 3 performed better than the original Brief-BESTest (Model 1) and Model 2. Table 3 summarizes the goodness of fit indices of each model and the significance level of the comparison between each model pair.

The factor loadings of each item were significant $(p<0.001)$ and higher than 0.6 for all three models. Item 1 (Hip/Trunk Lateral Strength), when present, and item 2 (FR Forward) had the lowest factor loading.

\section{Internal consistency}

Cronbach's alpha was good for Brief-BESTest Models 1 (0.92) and 3 (0.92), but not for Model 2 ( 0.56 and 0.88 , respectively for static and dynamic balance factor). Coefficient omega was higher 
287 than 0.80 only for Model 3, while Model $1(0.75)$ and Model 2 (0.71 and 0.61 , respectively for 288 static and dynamic balance factor) showed a lower coefficient, thus suggesting that only Model 3 289 had good internal consistency.

The total score of the Brief-BESTest needs to be weighted considering the loading coefficient of each item. Therefore, scores were adjusted to yield a uniform score range 0-24 for all three models, where 0 represents severe impairment and 24 no balance impairment. Below are the weighted total score equations used to estimate Models 2 and 3:

Brief-BESTest (Model 2) $=$

$(0.860504 *$ item 1$)+(0.914286 *$ item 2$)+(1.089076 *$ item 3$)+(1.048739 *$ item 4$)+(1.021849 *$ item 5$)+$ $(0.994958 *$ item6)+(1.008438*item 7$)+(1.062185 *$ item8)

Brief-BESTest (Model 3) $=$ $(0.963107 *$ item 2$)+(1.133981 *$ item3 $)+(1.118447 *$ item4 $)+(1.21165 *$ item5 $)+(1.165049 *$ ite 6$)+$ $(1.165049 *$ item $)+(1.242718 *$ item 8$)$

\section{Convergent validity}

The relationship of the total score estimated by the three different models of Brief-BESTest and the $A B C$ 5-levels scale was rho $=0.62(95 \%$ C.I. $=0.55-0.70)$ for Model 1 , rho $=0.61(95 \%$ C.I. $=$ 0.54-0.69) for Model 2 and rho $=0.61(95 \%$ C.I. $=0.54-0.69)$ for Model 3. No significant $(p=0.85)$ difference was found between the three Spearman correlation coefficients.

\section{Discriminant validity}

Figure 2 shows the ROC curve plotted to assess the ability of the three models of Brief-BESTest to discriminate between patients with vs. without a history of falls. Table 4 reports the 
305 discrimination parameters (cut-off scores) for Models 1, 2 and 3 and for the simple balance tests 306 (OLS, TUG test and FR). The AUC was $0.72(95 \%$ C.I. $=0.66-0.78)$ for all three models. Model 3 307 showed superior sensitivity, specificity and likelihood ratios compared to the other two 1308

\section{DISCUSSION}

The main purpose of this study was to compare, in a large group of patients with balance disorders, the structural, convergent and discriminant validity of three different models of the Brief-BESTest. The Brief-BESTest, in particular Model 3, was found to be unidimensional and to have a good convergent validity with other measures of balance confidence. In addition, the Brief-BESTest confirmed its ability to distinguish subjects with a history of falling from those without a history of falling, in contrast to other simple balance tests.

\section{Structural validity}

CFA showed that measurement properties of the original Brief-BESTest scale (Model 1) [13] little fitted our data; none of CFA performance indices reached satisfactory values. As suggested in a previous study [14], the original Brief-BESTest can be improved by making the following modifications: a) removing item 1; b) covarying errors between items 3 and 4 and between items 5 and 6; c) using an appropriate weighting method for the calculation of the total score. The internal structure of the scale can, in fact, be improved by removing item 1 rather than by 
327 increasing the number of factors as proposed earlier [19]. The analysis of structural validity 328 prompted two main considerations. First, item 1 does not belong to the same construct as the 329 other items. This finding, in line with previous studies $[14,19]$, is also supported by the fact that 330 "lift a leg to the side of the body" (item 1) could reflect a general reduction in strength rather 12 because no advantage in terms of fitting performance was found when more than one factor was taken into consideration. In other words, our study confirmed that the Brief-BESTest is not able to measure multiple dimensions of balance as claimed by [13]. The Brief-BESTest items include all subsections covered by the BESTest, but this does not mean that the two scales have the same capability to measure the different aspects underlying postural control. In accordance with other authors, one could object that a unidimensional tool is a poor representation of the balance concept, which by definition is multidimensional. We agree with this objection and believe that the Brief-BESTest can assess only certain aspects of dynamic balance. It neglects static components of balance such as those measured by the "Romberg test". On the other hand, some aspects of balance considered independent in animal models [48], such as walking and maintenance of upright position, could be actually considered aswell belonging to the same construct in humans. In fact, balance control and locomotion are interdependent at many different levels of the central nervous system and these functions share some common principles of organization $[49,50]$. Furthermore, previous studies have reported that the ability to maintain upright stance could be related to walking $[51,52,53]$ in patients affected by balance disorders. Hence, in these patients it might be misleading for a clinical scale to investigate balance and walking as two separate factors, as also suggested by recent recommendations [54].

\section{Internal consistency}


350 Despite the large consensus in the psychometric literature that coefficient omega should be used 351 when scales are not congeneric and the assumptions of Cronbach's alpha are not met [41], no 352 previous study has reported omega values for the Brief-BESTest. This is the first study to report 353

good internal validity. On the contrary, Cronbach's alpha values were found to be good for both

Model 1 and 3. Our values of alpha are similar to those reported by [13], and to other studies in both orthopaedic [55] and neurological patients [56]. It is well known that Cronbach's alpha is a function of the number of items. In this regard, it is interesting to note that Model 3, despite its lower number of items, reaches a higher value of internal consistency than the other models.

This should denote a superior internal consistency of Model 3.

The discrepancy between the results for Cronbach's alpha and those for coefficient omega can be explained by the fact that the former has been frequently demonstrated to attain quite high values even when the items are measuring different latent variables [57]. On the contrary, the coefficient omega is able to highlight the presence of items that do not belong to the same latent variable. As for the Brief-BESTest, the low values of coefficient omega found for Model 1 could be due to the presence of item 1, which, as highlighted by CFA, seems not to belong to the same construct as the other items.

\section{Convergent validity}

The three models compared in this study exhibit an equivalent moderate convergent validity (Spearman's rho $=0.61$ ) with the $A B C 5$-levels scale. This finding confirms previous studies in which the Brief-BESTest showed a moderate correlation with $A B C$ in specific populations, such as chronic obstructive pulmonary disease [15], stroke [11] and cancer survivors patients [58]. This is 
372 not surprising since it is well known that balance confidence is a consequence of balance 373 impairments [59].

\section{Discriminant validity}

The three Brief-BESTest models exhibited an equallyivalent and acceptable accuracy (AUC $=0.72$ ) of the Brief-BESTest in distinguishing patients with vs. without history of falls. However, our AUCs are lower than those of [17], who found in patients with Parkinson's disease AUC values of 0.82, 0.86 and 0.84 respectively for the Brief-BESTest, Mini-BESTest and BESTest, thus indicating a moderate accuracy of the three scales in recognising a history of falls. Likely, the small difference is due to the heterogeneity of our patients. It We cannot be excluded that studying separate disease populations might improve the discriminant validity.

In accordance line with previous studies, we confirm that balance scales can discriminate between fallers and non-fallers, in contrast to single balance tests which have a we found a low level of accuracy in identifying fallers using only a single balance test $[11,60,61]$. Due to the heterogeneity of patients in our study, it is unlikely that a single test could accurately identify patients at risk of falls. This is in line with recommendations of [62] who suggested to use two or more clinical tests for an accurate evaluation of the various components of risk of falls in patients with Parkinson's disease. The limited association between single measures of balance and fall history could be partly explained bydue to the multifactorial nature of causes of fall.

\section{Study limitations}

Our study was based on a heterogeneous population sample of patients affected by different balance disorders that are representative of the spectrum of neurological diseases routinely 
394 observed in departments of rehabilitation, but may not be representative of other clinical

settings. Although the Brief-BESTest assesses balance performance independently of the

pathology that causes the problem, future studies should assess psychometric characteristics

such as responsiveness, the minimal clinically important difference and sensitivity to change of

the Brief-BESTest in specific groups of disease.

The history of falls should be considered useful only for discriminative purposes (i.e. to distinguish fallers from non-fallers) and not to predict patients who will fall in the future. In fact, falls change people's behavior and the cutoff scores for prospective prediction of falls may be very different from those reported in our study.

\section{Implications for clinical practice and conclusions}

The comparison of the three structural models of Brief-BESTest proposed in the literature clearly highlights that Model 3, i.e. the shortest version, has psychometric characteristics equal or superior to the other two. This makes Model 3 the best of the three versions to recommend for use in clinical practice, given that it is also the fastest to perform. For this reason, in the supplementary material we provide a simple calculator for the three models tested in this study. Finally, this study highlights once again the superiority of a clinical scale composed of several items compared to single-item measures.

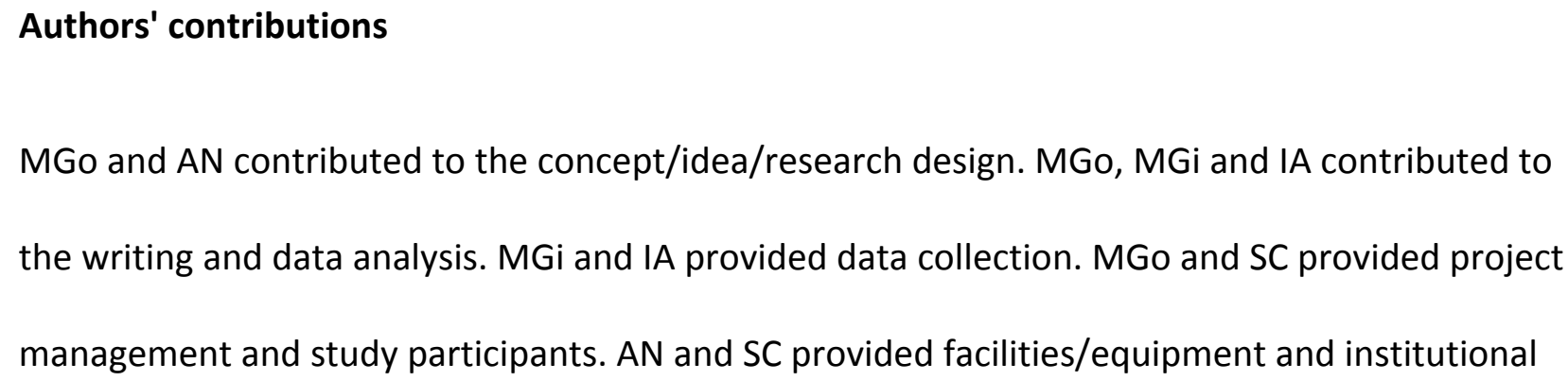
the writing and data analysis. MGi and IA provided data collection. MGo and SC provided project management and study participants. AN and SC provided facilities/equipment and institutional 
416 liaisons. SC and RC contributed consultation in different phases of the study (including review of 417 manuscript before submission).

\section{Ethical Approval}

The Scientific Technical Committee of the Istituti Clinici Scientifici Maugeri approved this study with the following identification number: rrf41.

\section{Funding}

This research did not receive any specific grant from funding agencies in the public, commercial, or not-for-profit sectors.

\section{Conflict of Interest}

None declared.

\section{Bibliography}

[1] Geiger RA, Allen JB, O'Keefe J, Hicks RR. Balance and mobility following stroke: effects of physical therapy interventions with and without biofeedback/forceplate training. Phys Ther 2001;81(4):995-1005. PubMed PMID: 11276182.

[2] Hyndman D, Ashburn A. People with stroke living in the community: Attention deficits, balance, ADL ability and falls. Disabil Rehabil 2003;25(15):817-22. PubMed PMID: 12851091. 
434 [3] Horlings CG, Van Engelen BG, Allum JH, Bloem BR. A weak balance: the contribution of muscle 435 weakness to postural instability and falls. Nat Rev Neurol. 2008;4(9):504. doi:

$436 \quad 10.1038 /$ ncpneuro0886.

[4] Sturnieks DL, St George R, Lord SR. Balance disorders in the elderly. Neurophysiol Clin 2008;38(6):467-478. doi: 10.1016/j.neucli.2008.09.001.

[5] Mancini M, Horak FB. The relevance of clinical balance assessment tools to differentiate balance deficits. Eur J Phys Rehabil Med 2010;46:239. PubMed PMID: 20485226.

[6] McGinnis PQ, Hack LM, Nixon-Cave K, Michlovitz SL. Factors that influence the clinical decision making of physical therapists in choosing a balance assessment approach. Phys Ther 2009;89:233. doi: 10.2522/ptj.20080131.

[7] Sibley KM, Straus SE, Inness EL, Salbach NM, Jaglal SB. Balance assessment practices and use of standardized balance measures among Ontario physical therapists. Phys Ther 2011;91:1583. doi: 10.2522/ptj.20110063.

[8] Horak FB, Wrisley DM, Frank J. The Balance Evaluation Systems Test (BESTest) to differentiate balance deficits. Phys Ther 2009;89:484-498. doi: 10.2522/ptj.20080071.

[9] Jacobs JV, Horak FB, Tran VK, Nutt JG. Multiple balance tests improve the assessment of postural stability in subjects with Parkinson's disease. J Neurol Neurosurg Psychiatry 2006;1;77(3):322-6. PubMed PMID: 16484639.

[10] Jacobs JV, Earhart GM, McNeely ME. Can postural instability tests improve the prediction of future falls in people with Parkinson's disease beyond knowing existing fall history? J Neurol 2016;263(1):133-9. doi: 10.1007/s00415-015-7950-x. 
455 [11] Tsang CS, Liao LR, Chung RC, Pang MY. Psychometric properties of the Mini-Balance $456 \quad$ Evaluation Systems Test (Mini-BESTest) in community-dwelling individuals with chronic 457 stroke. Phys Ther 2013;93:1102-15. doi: 10.2522/ptj.20120454.

[12] Franchignoni F, Horak F, Godi M, Nardone A, Giordano A. Using psychometric techniques to improve the Balance Evaluation Systems Test: the Mini-BESTest. J Rehabil Med 2010;42:323331. doi: 10.2340/16501977-0537.

[13] Padgett PK, Jacobs JV and Kasser SL. Is the BESTest at its best? A suggested brief version based on interrater reliability, validity, internal consistency, and theoretical construct. Phys Ther 2012;92:1197-1207. doi: 10.2522/ptj.20120056.

[14] Bravini E, Nardone A, Godi M, Guglielmetti S, Franchignoni F, Giordano A. Does the BriefBESTest meet classical test theory and Rasch analysis requirements for balance assessment in people with neurological disorders? Phys Ther 2016;96:1610-1619. PubMed PMID: 27103223.

[15] Jácome C, Cruz J, Oliveira A, Marques A. Validity, reliability, and ability to identify fall status of the Berg Balance Scale, BESTest, Mini-BESTest, and Brief-BESTest in patients with COPD. Phys Ther 2016;96(11):1807-1815. doi: 10.2522/ptj.20150391.

[16] Leddy AL, Crowner BE, Earhart GM. Utility of the Mini-BESTest, BESTest, and BESTest sections for balance assessments in individuals with Parkinson disease. J Neurol Phys Ther 2011;35:90-97. doi: 10.1097/NPT.0b013e31821a620c.

[17] Duncan RP, Leddy AL, Cavanaugh JT, Dibble LE, Ellis TD, Fors MP, Foreman KB, Earhart GM. Comparative utility of the BESTest, Mini-BESTest, and Brief-BESTest for predicting falls in 
476 individuals with Parkinson disease: a cohort study. Phys Ther 2013;93:542-550. doi:

$477 \quad 10.2522 / p t j .20120302$.

[18] O’Hoski S, Winship B, Herridge L, Agha T, Brooks D, Beauchamp MK, Sibley KM. Increasing the clinical utility of the BESTest, Mini-BESTest, and Brief-BESTest: normative values in Canadian adults who are healthy and aged 50 years or older. Phys Ther 2014;94:334-342. doi: 10.2522/ptj.20130104.

[19] Franchignoni F, Giordano A. On "Is the BESTest at its best?...." Padgett PK, Jacobs JV, Kasser SL. Phys Ther 2012;92:1197-1207. Phys Ther 2012;92(9):1236-7. doi: 10.2522/ptj.2012.92.9.1236.

[20] Marques A, Almeida S, Carvalho J, Cruz J, Oliveira A, Jácome C. Reliability, Validity, and Ability to Identify Fall Status of the Balance Evaluation Systems Test, Mini-Balance Evaluation Systems Test, and Brief-Balance Evaluation Systems Test in Older People Living in the Community. Arch Phys Med Rehabil 2016;97:2166-2173. doi: 10.1016/j.apmr.2016.07.011.

[21] McArdle JJ. Current directions in structural factor analysis. Curr Dir Psychol Sci 1996;5:11-18.

[22] Norman GR, Streiner DL. PMPH-USA. PDQ statistics; 1st edition, 2003.

[23] Jansen AC, van Aalst-Cohen ES, Hutten BA, Büller HR, Kastelein JJ, Prins MH. Guidelines were developed for data collection from medical records for use in retrospective analyses. J Clin Epidemiol 2005;58(3):269-274. doi: 10.1016/j.jclinepi.2004.07.006.

[24] Jernigan SD, Pohl PS, Mahnken JD, Kluding PM. Diagnostic accuracy of fall risk assessment tools in people with diabetic peripheral neuropathy. Phys Ther 2012;92:1461-1470. doi: 10.2522/ptj.20120070. 
497 [25] Lin MR, Hwang HF, Hu MH, Wu HDI, Wang YW, Huang FC. Psychometric comparisons of the 498 timed up and go, one-leg stand, functional reach, and Tinetti balance measures in 499 community-dwelling older people. J Am Geriatr Soc 2004;52:1343-1348. doi: 10.1111/j.1532$500 \quad$ 5415.2004.52366.x.

[26] Vellas BJ, Wayne SJ, Romero L, Baumgartner RN, Rubenstein LZ, Garry PJ. One-leg balance is an important predictor of injurious falls in older persons. J Am Geriatr Soc 1997;45:735-738. PubMed PMID: 9180669.

[27] Sebastião E, Sandroff BM, Learmonth YC, Motl RW. Validity of the timed up and go test as a measure of functional mobility in persons with multiple sclerosis. Arch Phys Med Rehabil 2016;97:1072-1077. doi: 10.1016/j.apmr.2015.12.031.

[28] Podsiadlo D, Richardson S. The timed 'Up \& Go': A test of basic functional mobility for frail elderly persons. J Am Geriatr Soc 1991;39:142-148. PubMed PMID: 1991946.

[29] Franchignoni F, Tesio L, Martino M, Ricupero C. Reliability of four simple, quantitative tests of balance and mobility in healthy elderly females. Aging Clin Exp Res 1998;10:26-31. PubMed PMID: 9589748.

[30] Duncan PW, Weiner DK, Chandler J, Studenski S. Functional reach: a new clinical measure of balance. J Gerontol 1990;45(6):M192-7. PubMed PMID: 2229941.

[31] Powell LE, Myers AM. The activities-specific balance confidence (ABC) scale. J Gerontol A Biol Sci Med Sci 1995;50(1):M28-M34. PubMed PMID: 7814786.

[32] Franchignoni F, Giordano A, Ronconi G, Rabini A, Ferriero G. Rasch validation of the Activities-specific Balance Confidence Scale and its short versions in patients with Parkinson's disease. J Rehabil Med 2014;46:532-539. doi: 10.2340/16501977-1808. 
519 [33] Atkinson TM, Rosenfeld BD, Sit L, Mendoza TR, Fruscione M, Lavene D, Shaw M, Li Y, Hay J, 520 Cleeland CS, Scher HI, Breitbart WS, Basch E. Using confirmatory factor analysis to evaluate 521 construct validity of the Brief Pain Inventory (BPI). J Pain Symptom Manage 2011;41(3):558-

[34] Bentler PM. Comparative fit indexes in structural models. Psychol Bull 1990;107(2):238-46. PubMed PMID: 2320703.

[35] Browne MW, Cudeck R. Alternative ways of assessing model fit. In: Bollen KA, Long JS, editors. Testing Structural Equation Models. Newbury Park: Sage 1993;136-62.

[36] Hu LT, Bentler P. Cutoff criteria for fit indices in covariance structure analysis: conventional criteria versus new alternatives. Struct Equ Model Multidiscip J 1999;6:1-55. doi: 10.1080/10705519909540118.

[37] DiStefano C, Zhu M, Mindrila D. Understanding and using factor scores: Considerations for the applied researcher. PARE 2009;14(20):1-11.

[38] Schönberger M, Ponsford J, Olver J, Ponsford, M. A longitudinal study of family functioning after TBI and relatives' emotional status. Neuropsychol Rehabil 2010;20:813-829. doi: 10.1080/09602011003620077.

[39] Hancock GR, Mueller RO. Rethinking construct reliability within latent variable systems. Structural equation modeling: Present and future-A Festschrift in honor of Karl Jöreskog. Lincolnwood, IL: Scientific Software International 2001;195-216.

[40] Cronbach $\amalg$. Coefficient alpha and the internal structure of tests. Psychometrika 1951;16(3):297-334. PubMed PMID: 8449658. 
540 [41] Dunn TJ, Baguley T, Brunsden V. From alpha to omega: a practical solution to the pervasive 541 problem of internal consistency estimation. Br J Psychol 2014;105:399-412. doi:

$542 \quad$ 10.1111/bjop.12046.

[42] Opheim A, Jahnsen R, Olsson E, Stanghelle JK. Balance in relation to walking deterioration in adults with spastic bilateral cerebral palsy. Phys Ther 2012;92(2):279-88. doi: 10.2522/ptj.20100432.

[43] Curtze C, Nutt JG, Carlson-Kuhta P, Mancini M, Horak FB. Objective gait and balance impairments relate to balance confidence and perceived mobility in people with Parkinson disease. Phys Ther 2016;96(11):1734-1743. PubMed PMID: 27149959.

[44] Rand D. Mobility, balance and balance confidence - correlations with daily living of individuals with and without mild proprioception deficits post-stroke. NeuroRehabilitation 2018;43(2):219-226. doi: 10.3233/NRE-172398.

[45] Salbach NM, Mayo NE, Hanley JA, Richards CL, Wood-Dauphinee S. Psychometric evaluation of the original and Canadian French version of the activities-specific balance confidence scale among people with stroke. Arch Phys Med Rehabil 2006;87(12):1597-604. PubMed PMID: 17141639.

[46] Cohen, J. Statistical power analysis for the behavioral sciences. 2nd edition, 1988.

[47] Akobeng AK. Understanding diagnostic tests 3: receiver operating characteristic curves. Acta Paediatr 2007;96:664-647. doi: 10.1111/j.1651-2227.2006.00178.x.

[48] Hodgson JA, Roy RR, de Leon R, Dobkin B, Edgerton VR. Can the mammalian lumbar spinal cord learn a motor task? Med Sci Sports Exerc 1994;26:1491-1497. PubMed PMID: 7869884. 
561 [49] Grasso R, Zago M, Lacquaniti F. Interactions between posture and locomotion: motor 562 patterns in humans walking with bent posture versus erect posture. J Neurophysiol 563 2000;83:288-300. doi: 10.1152/jn.2000.83.1.288.

[50] Massion J. Movement, posture and equilibrium: interaction and coordination. Prog Neurobiol 1992;38(1):35-56. Review. PubMed PMID: 1736324.

[51] Giardini M, Nardone A, Godi M, Guglielmetti S, Arcolin I, Pisano F, Schieppati M. Instrumental or physical-exercise rehabilitation of balance improves both balance and gait in Parkinson's disease. Neural Plast 2018;2018:5614242. doi: 10.1155/2018/5614242.

[52] Nardone A, Godi M, Grasso M, Guglielmetti S, Schieppati M. Stabilometry is a predictor of gait performance in chronic hemiparetic stroke patients. Gait Posture 2009;30(1):5-10. doi: 10.1016/j.gaitpost.2009.02.006.

[53] Morlino P, Balbi B, Guglielmetti S, Giardini M, Grasso M, Giordano C, Schieppati M, Nardone A. Gait abnormalities of COPD are not directly related to respiratory function. Gait Posture 2017;58:352-357. doi: 10.1016/j.gaitpost.2017.08.020.

[54] Bloem BR, Marinus J, Almeida Q, Dibble L, Nieuwboer A, Post B, Ruzicka E, Goetz C, Stebbins G, Martinez-Martin P, Schrag A; Movement Disorders Society Rating Scales Committee. Measurement instruments to assess posture, gait, and balance in Parkinson's disease: Critique and recommendations. Mov Disord 2016;31(9):1342-55. doi: 10.1002/mds.26572.

[55] Chan AC, Pang MY. Assessing balance function in patients with total knee arthroplasty. Phys Ther 2015;95(10):1397-407. doi: 10.2522/ptj.20140486. 
581 [56] Huang M, Pang MY. Psychometric properties of Brief-Balance Evaluation Systems Test (Brief582 BESTest) in evaluating balance performance in individuals with chronic stroke. Brain Behav 583 2017;7(3):e00649. doi: 10.1002/brb3.649.

[57] Revelle W, Zinbarg RE. Coefficients alpha, beta, omega, and the glb: Comments on Sijtsma. Psychometrika 2009;74(1):145. doi:10.1007/s11336-008-9102-z.

[58] Huang MH, Miller K, Smith K, Fredrickson K, Shilling T. Reliability, validity, and minimal detectable change of Balance Evaluation Systems Test and its short versions in older cancer survivors: a pilot study. J Geriatr Phys Ther 2016;39(2):58-63. doi: 10.1519/JPT.0000000000000047.

[59] Mak MK, Pang MY. Balance confidence and functional mobility are independently associated with falls in people with Parkinson's disease. J Neurol 2009;256:742-749. doi: 10.1007/s00415-009-5007-8.

[60] Cameron M, Mazumder R, Murchison C, King L. Mini Balance Evaluation Systems Test in people with multiple sclerosis: reflects imbalance but may not predict falls. Gait Posture 2014;39(1):669. doi: 10.1016/j.gaitpost.2013.08.009.

[61] Mak MK, Auyeung MM. The mini-BESTest can predict parkinsonian recurrent fallers: a 6month prospective study. J Rehabil Med 2013;45:565-571. doi: 10.2340/16501977-1144.

[62] Dibble LE, Christensen J, Ballard DJ, Foreman KB. Diagnosis of fall risk in Parkinson disease: an analysis of individual and collective clinical balance test interpretation. Phys Ther 2008;88:323-332. doi: 10.2522/ptj.20070082. 


\section{Table 1}

603 Demographic data and scores on balance measures for the entire sample, and fallers vs. non-

604 fallers.

\begin{tabular}{lcccc}
\hline & $\begin{array}{c}\text { Entire Total Sample } \\
\text { (N=416) }\end{array}$ & Fallers (N=135) & Non-fallers (N=160) & \multirow{2}{*}{$p$} \\
\cline { 2 - 4 } & $\mathrm{N} \%$ & $\mathrm{~N} \%$ & $\mathrm{~N} \%$ & \\
\hline Sex (M/F) & $55 / 45$ & $51 / 49$ & $58 / 42$ & $.23^{\mathrm{a}}$ \\
Walking Aid (no/yes) & $54 / 46$ & $47 / 53$ & $68 / 32$ & $<.001^{\mathrm{a}}$ \\
\cline { 2 - 4 } & Mean (SD) & Mean (SD) & Mean (SD) & \\
Age (y) & $66.5(14.2)$ & $66.3(13.4)$ & $64.4(14.8)$ & $.28^{\mathrm{b}}$ \\
OLS mean (s) & $4.2(6.3)$ & $3.3(5.0)$ & $6.9(7.5)$ & $<.001^{\mathrm{b}}$ \\
TUG test (s) & $17.6(15.3)$ & $20.6(20.3)$ & $13.3(9.5)$ & $<.001^{\mathrm{b}}$ \\
Functional Reach (cm) & $18.6(9.7)$ & $16.5(9.6)$ & $20.5(9.8)$ & $<.01^{\mathrm{b}}$ \\
Total score BBT & $8.9(6.4)$ & $7.3(5.1)$ & $11.8(6.9)$ & $<.001^{\mathrm{b}}$ \\
Total score ABC 5-levels & $29.6(16.8)$ & $26.0(15.0)$ & $36.2(17.1)$ & $<.001^{\mathrm{b}}$ \\
\hline
\end{tabular}

The total sample comprises all patients, i.e. those in whom a fall history was collected (the two subgroups fallers/non-fallers) as well as those in whom a fall history was not collected due to acute stroke event $(n=79)$ or failure to complete the questionnaire $(n=42)$, as this is a

retrospective study. Participants were classified as fallers if they reported $\mathbf{1} \mathbf{2}$ or more falls in the last 6 months.

SD, Standard Deviation; M, Male; F, Female; OLS, One Leg Stance; TUG test, Timed Up and Go test; BBT, Brief-BESTest; ABC 5-levels, Activities-specific Balance Confidence scale 5-levels of rating.

p-value was computed between fallers and non-fallers.

$\mathrm{a}=\chi^{2}$ test.

$\mathrm{b}=$ Mann-Whitney U-test. 


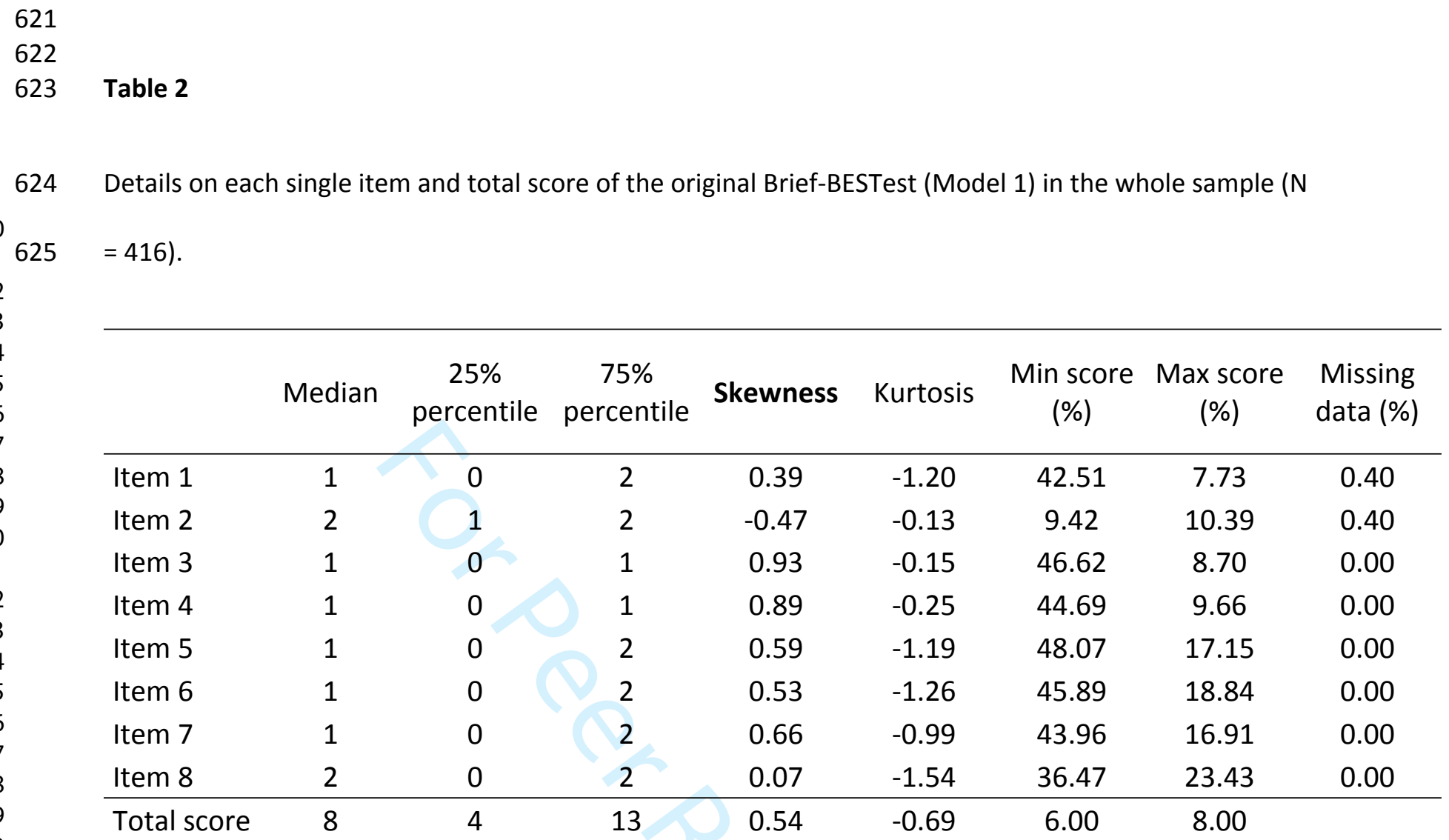

627 Item 1 - Hip/Trunk Lateral Strength; item 2 - Functional Reach Forward; item 3 and 4 - One Leg 34

35628 Stance, Left and Right; item 5 and 6 - Compensatory Stepping- Lateral, Left and Right; item 7 - 
631 Table 3

632 Summary of fit statistics of the specified models $(N=416)$

\begin{tabular}{|c|c|c|c|c|c|c|}
\hline Models & $\chi^{2}$ & df & RMSEA (90\% C.I.) & $\mathrm{CFI}$ & TLI & SRMR \\
\hline $\begin{array}{l}\text { Model } 1 \\
\text { (Padgett et al., 2012) }\end{array}$ & 134.0 & 20 & $0.12(0.10-0.14)$ & 0.78 & 0.70 & 0.09 \\
\hline $\begin{array}{l}\text { Model } 2 \\
\text { (adapted from Franchignoni \& Giordano, } \\
\text { 2012) }\end{array}$ & 60.3 & 18 & $0.08(0.06-0.10)$ & 0.92 & 0.88 & 0.05 \\
\hline $\begin{array}{l}\text { Model } 3 \\
\text { (adapted from Bravini et al., 2016) }\end{array}$ & 26.2 & 12 & $0.05(0.03-0.08)$ & 0.97 & 0.95 & 0.03 \\
\hline Comparison of factor models & \multicolumn{6}{|c|}{ Significant difference between models ${ }^{a}$} \\
\hline Model 1 vs. Model 2 & \multicolumn{6}{|c|}{$p<0.001$} \\
\hline Model 2 vs. Model 3 & \multicolumn{6}{|c|}{$p<0.001$} \\
\hline Model 3 vs. Model 1 & \multicolumn{6}{|c|}{$p<0.001$} \\
\hline
\end{tabular}

$634 \mathrm{df}$, degrees of freedom; RMSEA, Root Mean-Square Error of Approximation; C.I., Confidence 33

Interval; CFI, Comparative Fit Index; TLI, Tucker-Lewis Index; SRMSR, Standardized Root Mean

Square Residual.

a Calculated as a $\chi^{2}=\chi^{2}{ }_{2}-\chi^{2}{ }_{1}$ with $\mathrm{df}=\mathrm{df}_{2}-\mathrm{df}_{1}$. 


\section{Table 4}

641 Ability of the Brief-BESTest Models 1, 2 and 3 to discriminate fallers from non-fallers compared to

642 other measures of balance (OLS, TUG test, Functional Reach and ABC 5-levels) $(\mathbf{N}=\mathbf{2 9 5})$.

\begin{tabular}{lcccccc}
\hline Classification & $\begin{array}{c}\text { Brief-BESTest } \\
\text { Model 1 }\end{array}$ & $\begin{array}{c}\text { Brief-BESTest } \\
\text { Model 2 }\end{array}$ & $\begin{array}{c}\text { Brief-BESTest } \\
\text { Model 3 }\end{array}$ & OLS & TUG test & FR \\
\hline Cut-off score & 8 & 8 & 7 & 2 & 12 & 19 \\
AUC (95\% C.I.) & 0.72 & 0.72 & 0.72 & 0.63 & 0.62 & 0.61 \\
Sensitivity & $(0.66-0.78)$ & $(0.66-0.78)$ & $(0.66-0.78)$ & $(0.55-0.70)$ & $(0.56-0.68)$ & $(0.52-0.69)$ \\
Specificity & $74 \%$ & $72 \%$ & $74 \%$ & $63 \%$ & $68 \%$ & $67 \%$ \\
LR+ & $54 \%$ & $58 \%$ & $58 \%$ & $55 \%$ & $53 \%$ & $49 \%$ \\
LR- & 1.61 & 1.72 & 1.76 & 1.42 & 1.45 & 1.33 \\
Correctly Classified & $65 \%$ & $6.4 \%$ & $67 \%$ & $59 \%$ & $60 \%$ & $58 \%$ \\
\hline
\end{tabular}

OLS, One Leg Stance; TUG test, Timed Up and Go test; FR, Functional Reach; AUC, Area Under the Curve; C.I., Confidence Interval; LR+, positive Likelihood Ratio; LR-, negative Likelihood Ratio. 


\section{Appendix 1}

649 Items and factors of the three models of Brief-BESTest.

\begin{tabular}{l|c|c|c}
\hline $\begin{array}{l}\text { Model item } \\
\text { (Scoring 0-3 per item) }\end{array}$ & Model 1 & Model 2 & Model 3 \\
\hline Item 1: Hip/Trunk Lateral Strength & & Static Balance & \\
$\begin{array}{l}\text { Item 2: Functional Reach Forward } \\
\text { Item 3: Stand on One Leg-Left }\end{array}$ & & \\
Item 4: Stand on One Leg-Right & Dynamic Balance & & \multirow{2}{*}{ Dynamic Balance } \\
Item 5: Compensatory Stepping-Lateral, Left & & Dynamic Balance & \\
Item 6: Compensatory Stepping-Lateral, Right & & & \\
Item 7: Stand on foam surface with Eyes Closed & & $\begin{array}{c}0-24 \\
\text { (Static 0-5; } \\
\text { Item 8: Timed Up and Go test }\end{array}$ & \\
\hline Total score & & $0-24$ & $0-24$ \\
\hline
\end{tabular}




\section{Items}

Item 1: Hip/Trunk Lateral Strength

Item 2: Functional Reach Forward

Item 3: Stand on One Leg-Left

Item 4: Stand on One Leg-Right

Item 5: Compensatory Stepping-Lateral, Left

Item 6: Compensatory Stepping-Lateral, Right

Item 7: Stand on foam surface with Eyes Closed

Item 8: Timed Up and Go test

Total score (range 0-24)

Static Balance (range 0-5)

Dynamic Balance (range 0-19)

* to obtain the total Score of Model 3 is not necessary the score of item 1 
2

3

4

5

6

7

8

9

10

11

12

13

14

15

16

17

18

19

20

21

22

23

24

25

27

28

29

30

31

32

33

34

35

36

37

39

40

41

42

43

44

45

46

47

48

49

50

51

52

53

54

55

56

57

58

59

60

PTJ Manuscript in Review 
2

3

4

5

6

7

8

9

10

11

12

13

14

15

16

17

18

19

20

21

22

23

24

25

27

28

29

30

31

32

33

34

35

36

37

39

40

41

42

43

44

45

46

47

48

49

50

51

52

53

54

55

56

57

58

59

60

PTJ Manuscript in Review 

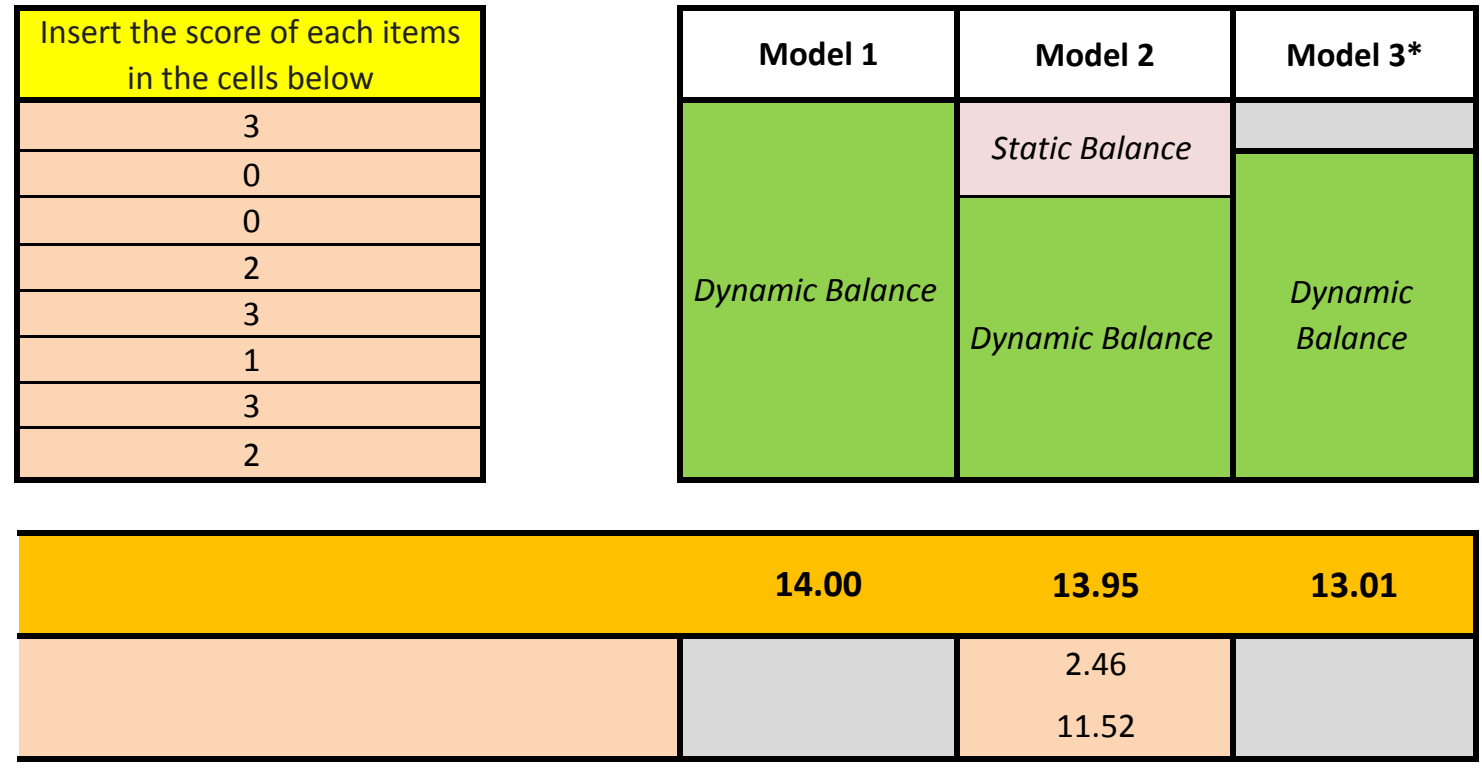
2

3

4

5

6

7

8

10

11

12

13

14

15

16

17

18

19

20

2

22

23

24

25

27

28

29

30

31

32

33

34

35

36

37

39

40

41

42

43

44

45

46

47

48

49

50

51

52

53

54

55

56

57

58

59

60

PTJ Manuscript in Review 
2

3

4

5

6

7

8

10

11

12

13

14

15

16

17

18

19

20

2

22

23

24

25

27

28

29

30

31

32

33

34

35

36

37

39

40

41

42

43

44

45

46

47

48

49

50

51

52

53

54

55

56

57

58

59

60

PTJ Manuscript in Review 
55

56

57

58

59 
2

3

4

5

6

7

8

9

10

11

12

13

14

15

16

17

18

19

20

21

22

23

24

25

26

27

28

29

30

31

32

33

34

35

36

37

43

44

45

46

47

48

49

50

51

52

53

54

55

56

57

58

59

60

PTJ Manuscript in Review 
2

3

4

5

6

7

8

9

10

11

12

13

14

15

16

17

18

19

20

21

22

23

24

25

26

27

28

29

30

31

32

33

34

35

36

37

43

44

45

46

47

48

49

50

51

52

53

54

55

56

57

58

59

60

PTJ Manuscript in Review 
2

3

4

5

6

7

8

9

10

11

12

13

14

15

16

17

18

19

20

21

22

23

24

25

26

27

28

29

30

31

32

33

34

35

36

37

43

44

45

46

47

48

49

50

51

52

53

54

55

56

57

58

59

60

PTJ Manuscript in Review 
2

3

4

5

6

7

8

9

10

11

12

13

14

15

16

17

18

19

20

21

22

23

24

25

26

27

28

29

30

31

32

33

34

35

36

37

43

44

45

46

47

48

49

50

51

52

53

54

55

56

57

58

59

60

PTJ Manuscript in Review 
2

3

4

5

6

7

8

10

11

12

13

14

15

16

17

18

19

20

21

22

23

24

25

27

28

29

30

31

32

33

34

35

36

37

39

40

41

42

43

44

45

46

47

48

49

50

51

52

53

54

55

56

57

58

59

60

PTJ Manuscript in Review 
2

3

4

5

6

7

8

9

10

11

12

13

14

15

16

17

18

19

20

21

22

24

25

26

27

28

29

30

31

32

33

34

35

36

37

39

40

41

42

43

44

45

46

47

48

49

50

51

52

53

54

55

56

57

58

59

60

PTJ Manuscript in Review 
2

3

4

5

6

7

8

9

10

11

12

13

14

15

16

17

18

19

20

21

22

24

25

26

27

28

29

30

31

32

33

34

35

36

37

39

40

41

42

43

44

45

46

47

48

49

50

51

52

53

54

55

56

57

58

59

60

PTJ Manuscript in Review 

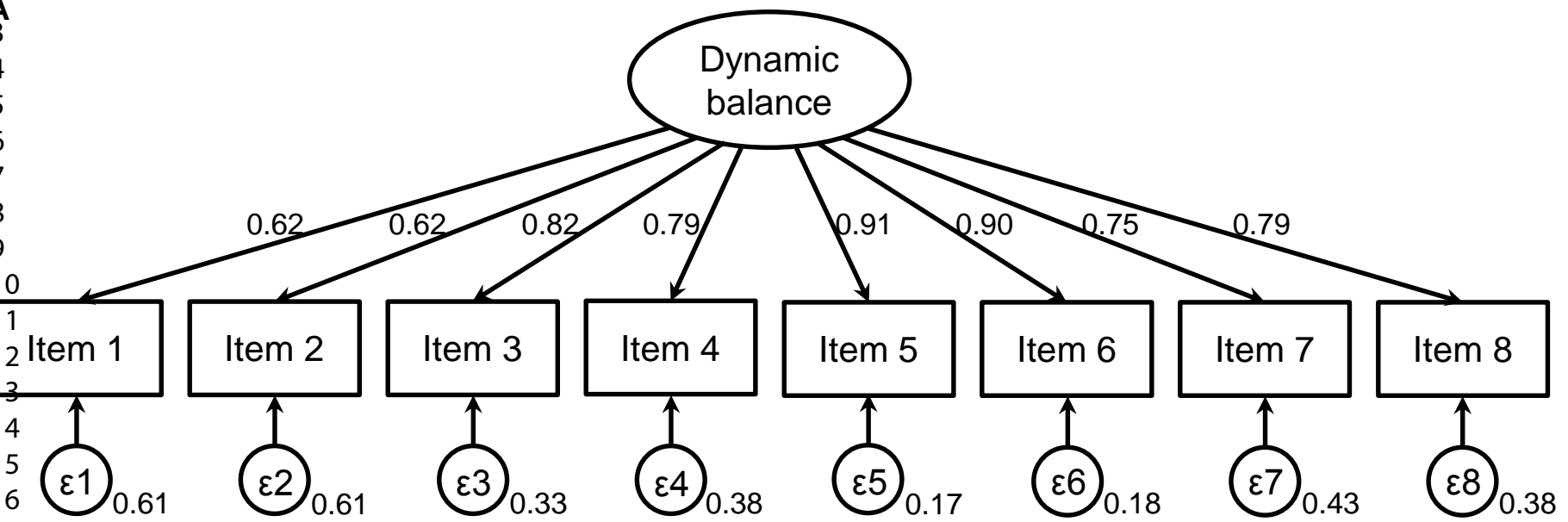

$\beta_{9}^{18}$

20

21

22

23
24
25

25
26

27

2

30

3

\begin{tabular}{l}
3 \\
3 \\
\hline
\end{tabular}

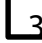

3

3

35
36
37

37

38

e

40

41

42

43

Static balance

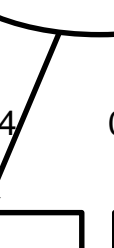

0.60

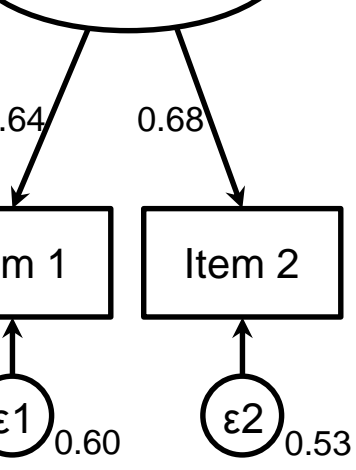

97
40
1
3
4
5
46
4
4
50
51
52
53
5
5
5
5
5
5
5
5
5
5
5
5
5
5
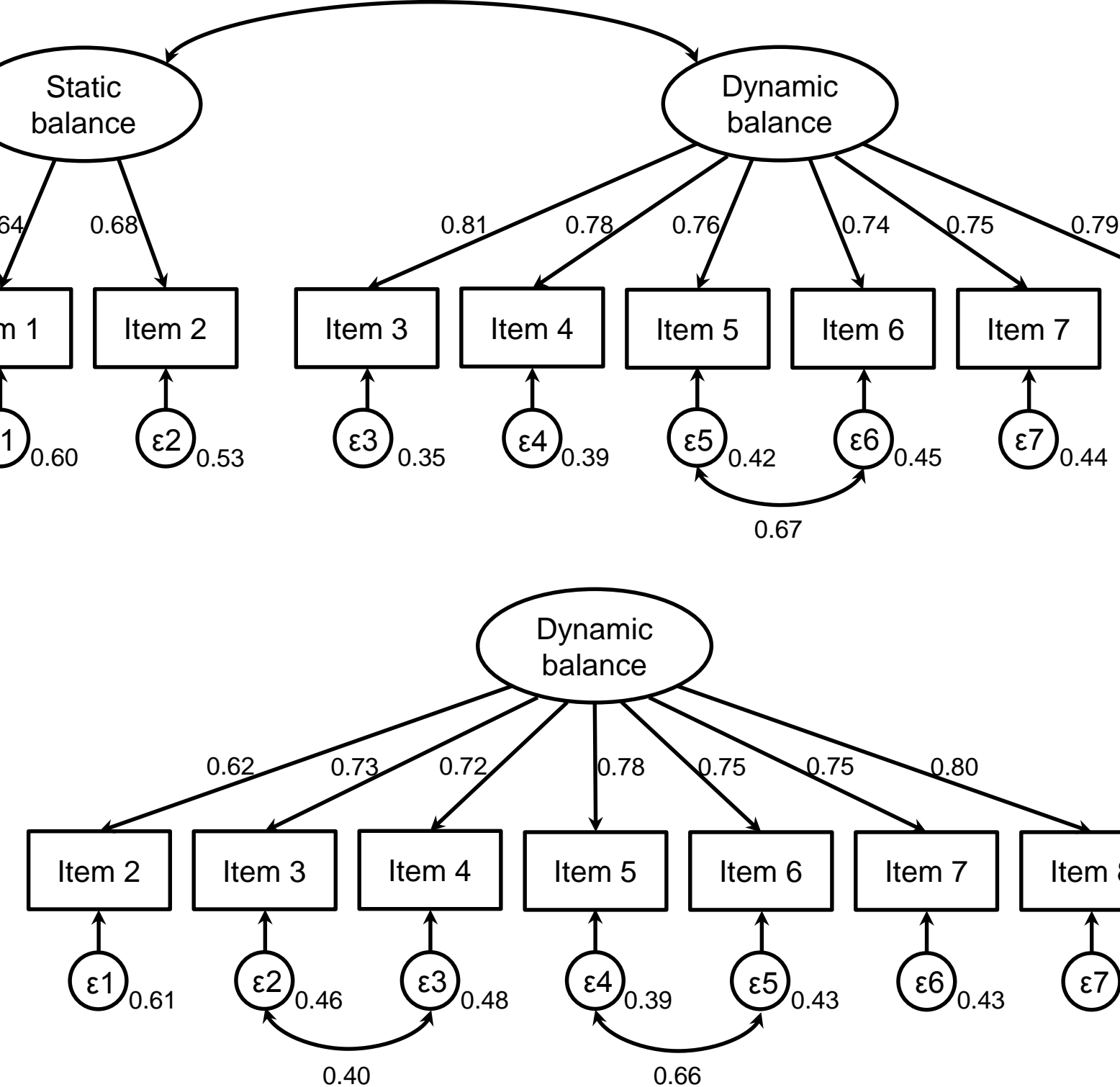

0.92

Dynamic

balance 


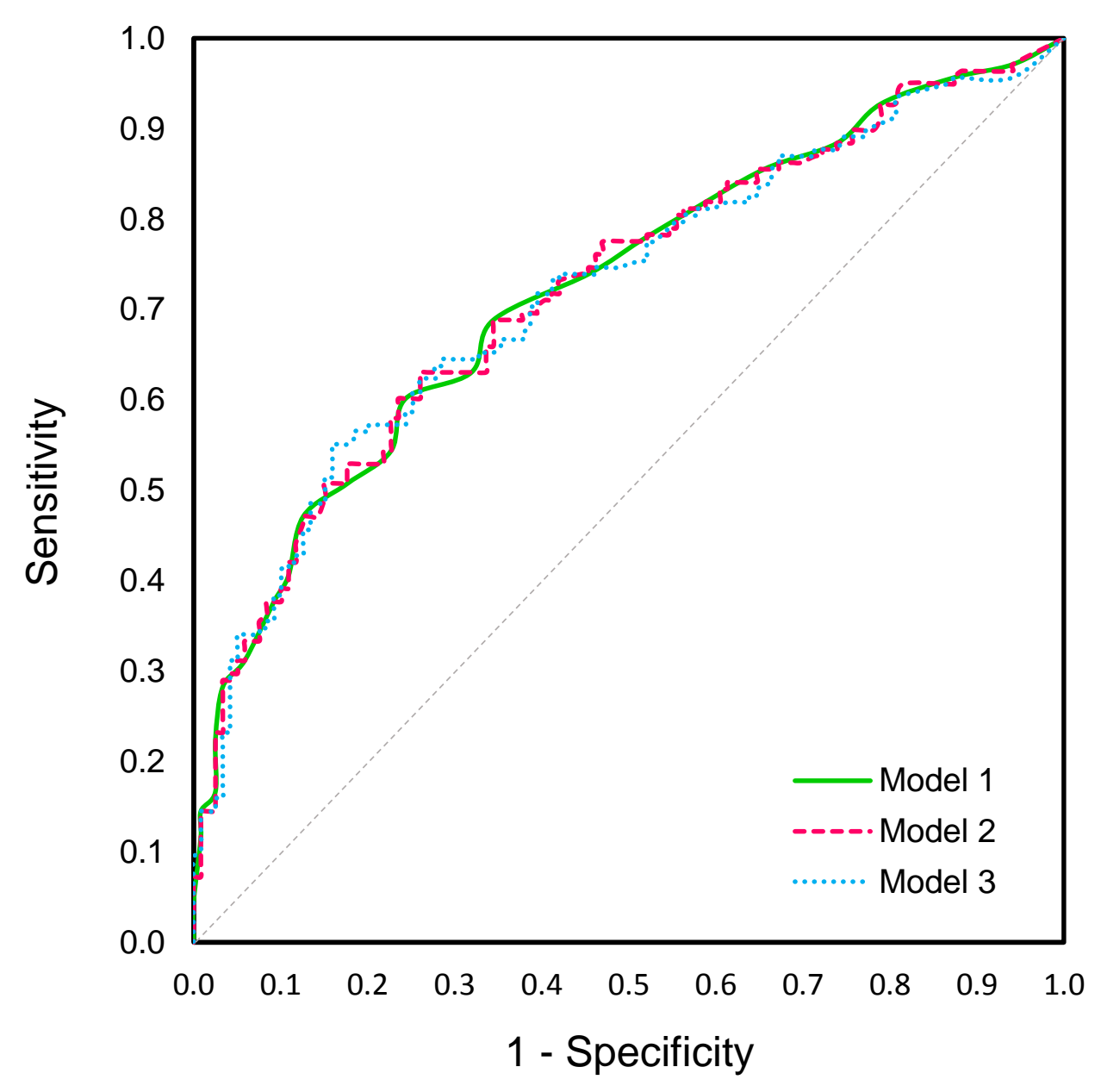

